\title{
El sistema lacustre de la Formación Mollar en el depocentro triásico de Santa Clara (provincia de Mendoza, Argentina)
}

\author{
Luis A. Spalletti ${ }^{1}$, Ana María Zavattieri ${ }^{2}$
}

I Centro de Investigaciones Geológicas, Facultad de Ciencias Naturales y Museo, Universidad Nacional de La Plata y Consejo Nacional de Investigaciones Cientificas y Técnicas, Calle 1, No. 644, B1900TAC La Plata, Argentina.

spalle@cig.museo.unlp.edu.ar

2 Laboratorio de Paleopalinología, Instituto Argentino de Nivología, Glaciología y Ciencias Ambientales, Centro Cientifico Tecnológico-Consejo Nacional de Investigaciones Cientificas y Técnicas, Casilla de Correo 330, 5500 Mendoza, Argentina.

amz@mendoza-conicet.gov.ar

RESUMEN. El depocentro triásico de Santa Clara, Cuenca Cuyana, se caracteriza por espesos depósitos generados en ambiente lacustre. Uno de ellos, con un registro de más de 345 m, corresponde a la Formación Mollar. El tramo inferior a medio está caracterizado por una monótona sucesión de lutitas bituminosas acumuladas por decantación suspensiva en el 'offshore' anóxico de un cuerpo lacustre hidrológicamente cerrado y que muestra alto contenido de materia orgánica amorfa de origen algal y de restos de plantas terrestres muy degradadas junto a sulfuros de hierro autígenos. Intercalan areniscas finas debidas a corrientes de turbidez diluidas y carbonatos estromatolíticos. En esta sucesión se definen ciclos granocrecientes de pequeña escala (PACs) que se atribuyen a episodios de expansión-retracción lacustre controlados por cambios climáticos. Asociaciones de facies heterolíticas representan los depósitos de la transición entre los ambientes de 'nearshore' y 'offshore' lacustre. La sección superior de la Formación Mollar se compone de sucesiones pelíticas con profusa bioturbación que sugieren mayor oxigenación del sustrato y se asignan a ambiente de costa afuera de un sistema lacustre holomíctico hidrológicamente abierto. Intercalan areniscas producto de flujos hiperpicnales. Depósitos de areniscas con abundantes trazas fósiles y estructuras de olas y flujos unidireccionales, representan a sectores marginales del ambiente lacustre. Además de los ciclos de alta frecuencia, en la Formación Mollar se definen tres secuencias asimétricas de mayor escala atribuidas a episodios mayores de expansión-contracción lacustre debidos a la interacción entre factores climáticos y tectónicos. El diseño de superposición granocreciente de la Formación Mollar y la gradual transición a depósitos fluviales de la sobreyacente Formación Montaña refleja asimismo una constante reducción del espacio de acomodación sedimentaria en el depocentro de Santa Clara a medida que se produjo la acumulación de los depósitos estudiados.

Palabras claves: Sistemas lacustres, Sedimentación cíclica, Palinofacies, Argentina, Triásico. 


\begin{abstract}
The lacustrine system of the Mollar Formation in the Triassic Santa Clara Depocenter (Mendoza Province, Argentina). The Triassic Santa Clara depocenter, Cuyo Basin, is characterised by thick fine-grained deposits formed in lacustrine systems. One of them, represented by the Mollar Formation, exceeds the $345 \mathrm{~m}$. The lower to middle section of this unit is dominated by a monotonous succession of black shales having a high content of amorphous organic matter produced by algae and highly degraded plant remains. These deposits were formed by suspension fallout in the anoxic 'offshore' sector of a hydrologically closed lake. Thin and fine-grained turbiditic beds and stromatolitic carbonates are intercalated in the fine-grained succession. Small-scale coarsening-upward cycles (PACs) are attributed to episodes of lake expansion-retraction driven by climate change. A facies association composed of an heterolithic package represents the deposits of the transition between 'nearshore' and 'offshore' settings. The upper section of the Mollar Formation essentially consists of bioturbated mudstones suggesting a greater oxygenation of the substrate. They are assigned to the 'offshore' environment of a holomictic hydrologically open lake system. Sporadic hyperpycnal flows are documented by intercalations of sandy turbidites. Bioturbated sandstone beds with primary structures indicative of both normal and storm wave action and unidirectional flows, represent the marginal deposits of the lacustrine system. In addition to the high-frequency cycles, three larger scale asymmetrical sequences are identified in the Mollar Formation. These sequences suggest episodes of major expansion-contraction of the lake system due to the interaction between climatic and tectonic factors. The overall shallowing up stacking pattern of the Mollar Formation and the gradual transition to fluvial deposits of the overlying Montaña Formation reflects a steady reduction of accommodation space in the Santa Clara depocenter during the accumulation of the studied succession.
\end{abstract}

Keywords: Lacustrine systems, Cyclic sedimentation, Palynofacies, Argentina, Triassic.

\section{Introducción}

Durante el Triásico, la región ubicada a lo largo del margen occidental de Gondwana se caracterizó por el desarrollo de un conjunto de cuencas sedimentarias angostas y elongadas en sentido NO-SE en las que se produjo la acumulación de un espeso registro de depósitos dominantemente continentales (Kokogián et al., 1999, 2001; Spalletti, 1999, 2001a). Estas cuencas se desarrollaron como consecuencia de un intenso proceso extensional (Charrier, 1979; Uliana y Biddle, 1988; Suárez y Bell, 1992) relacionado con procesos de adelgazamiento cortical y distensión posterior a fenómenos de colisión registrados durante el Paleozoico tardío (Mpodozis y Kay, 1990; Ramos y Kay, 1991; Tankard et al., 1995). Por tanto, las cuencas triásicas del oeste de Gondwana constituyen sistemas de rift pasivos (Uliana et al., 1989; Tankard et al., 1995; Spalletti, 2001a) con geometría de hemigrábenes (Legarreta y Gulisano, 1989; López Gamundí, 1994), es decir, con perfiles estructurales y de acumulación fuertemente asimétricos. Una de estas cuencas sedimentarias triásicas, muy posiblemente la más importante por su desarrollo regional y por sus yacimientos de hidrocarburos, es la Cuenca Cuyana (cf. Kokogián et al., 1988, 1993).

El régimen extensional de las cuencas triásicas del oeste de la Argentina y su muy común aislamiento del océano proto-Pacífico favoreció el desarrollo de un espeso registro sedimentario continental, caracterizado por la aparición de sucesiones dominantemente silicoclásticas. En los sectores internos de los depocentros ha sido muy común la generación de cuerpos lacustres, caracterizados por sucesiones de grano fino de amplia distribución areal que se localizan en distintos niveles estratigráficos.

Así ocurre en la región de Santa Clara, ubicada en el sector norte de la provincia de Mendoza (Fig. 1), sobre el flanco oriental de la Precordillera, donde aparece uno de los depocentros de la Cuenca Cuyana y en cuya sucesión sedimentaria netamente silicoclástica se registran varias unidades estratigráficas en las que dominan los depósitos lacustres, tales como las formaciones Cacheuta (Morel, 1994), Agua de la Zorra (Harrington, 1971), Carrizalito (Barredo y Ramos, 1997) y Cerro Puntudo (López-Gamundí y Astini, 2004). Una de dichas unidades, caracterizada por un importante espesor -que supera los $350 \mathrm{~m}$ - es la Formación Mollar. El objetivo del presente trabajo es describir la sucesión lacustre triásica de esta unidad estratigráfica con la intención de avanzar en su modelado paleoambiental sobre la base del análisis de sus facies sedimentarias y su contenido paleontológico.

\section{Ubicación, geología y estratigrafía de la región de Santa Clara}

La región de Santa Clara se ubica en el extremo norte de la provincia de Mendoza, entre los 68 $58^{\prime} y$ 
$69^{\circ} 03^{\prime}$ de longitud oeste y los $32^{\circ} 07^{\prime}$ y $32^{\circ} 11^{\prime}$ de latitud sur (Figs. 1 y 2). Esta área forma parte de la provincia geológica de la Precordillera y se caracteriza por una serie de afloramientos de las sucesiones triásicas que forman parte del sistema de depocentros extensionales de la denominada Cuenca Cuyana. La caracterización original de la sucesión triásica de Santa Clara, así como su ordenamiento estratigráfico, fueron efectuadas por Nesossi (1945) en su tesis doctoral inédita, y por Harrington (1953, in Stipanicic y Marsicano, 2002), Stipanicic (1969) y Harrington (1971). Los dos primeros autores atribuyeron la sucesión al Pérmico, aunque Harrington (1971) también destaca la presencia de peces de agua dulce triásicos que fueron descritos por Bordas (1944) y también estudiados por Hutchinson (1973), Breglia (2000) y revisados taxonómicamente por López Arbarello y Zavattieri (2008); además Harrington y Benedetti (1941) ya habían asignado estas sucesiones al Triásico Tardío en la zona aledaña más al sur. Fue, sin embargo, Stipanicic (1969) quien reubicó definitivamente en el Triásico los depósitos sedimentarios de la región de Santa Clara sobre la base de la fauna de peces dulceacuícolas y las floras fósiles. Para esta área el registro triásico es conocido como Grupo Peñasco (Stipanicic, 1979, 1983; Stipanicic et al., 2002), el que -tal como se ilustra en la figura 3 y de base a techo- está constituido por las formaciones Cielo, Mollar, Montaña, Santa Clara Abajo y Santa Clara Arriba (Harrington, 1953, in Stipanicic y Marsicano, 2002; Stipanicic, 1969; Harrington, 1971). Stipanicic et al. (2002) indican que esta sucesión se apoya en discordancia angular sobre sedimentitas y metamorfitas paleozoicas de distintas edades o sobre volcanitas del Grupo Choiyoi, mientras que es cubierta en discordancia por sedimentos del Cenozoico y Cuaternario. En realidad, y tal como lo indicaran Nesossi (1945), Yrigoyen y Stover (1969), Harrington (1971) y Cucchi (1972), las principales relaciones de tope del conjunto triásico de Santa Clara se dan mediante fallas sobre las que aparecen las leptometamorfitas eopaleozoicas del Grupo Villavicencio y las sedimentitas cenozoicas (Fig. 2). Es importante destacar, además, que resulta bastante difícil establecer las relaciones entre las distintas formaciones que conforman el Grupo Peñasco, dado que el área de afloramientos aparece fuertemente deformada tanto por fallas regionales y subregionales como por plegamiento.

\section{Caracteres generales de la Formación Mollar}

La Formación Mollar, objeto del presente trabajo, se caracteriza por una sucesión de más de $350 \mathrm{~m}$ de espesor que aparece intercalada entre depósitos

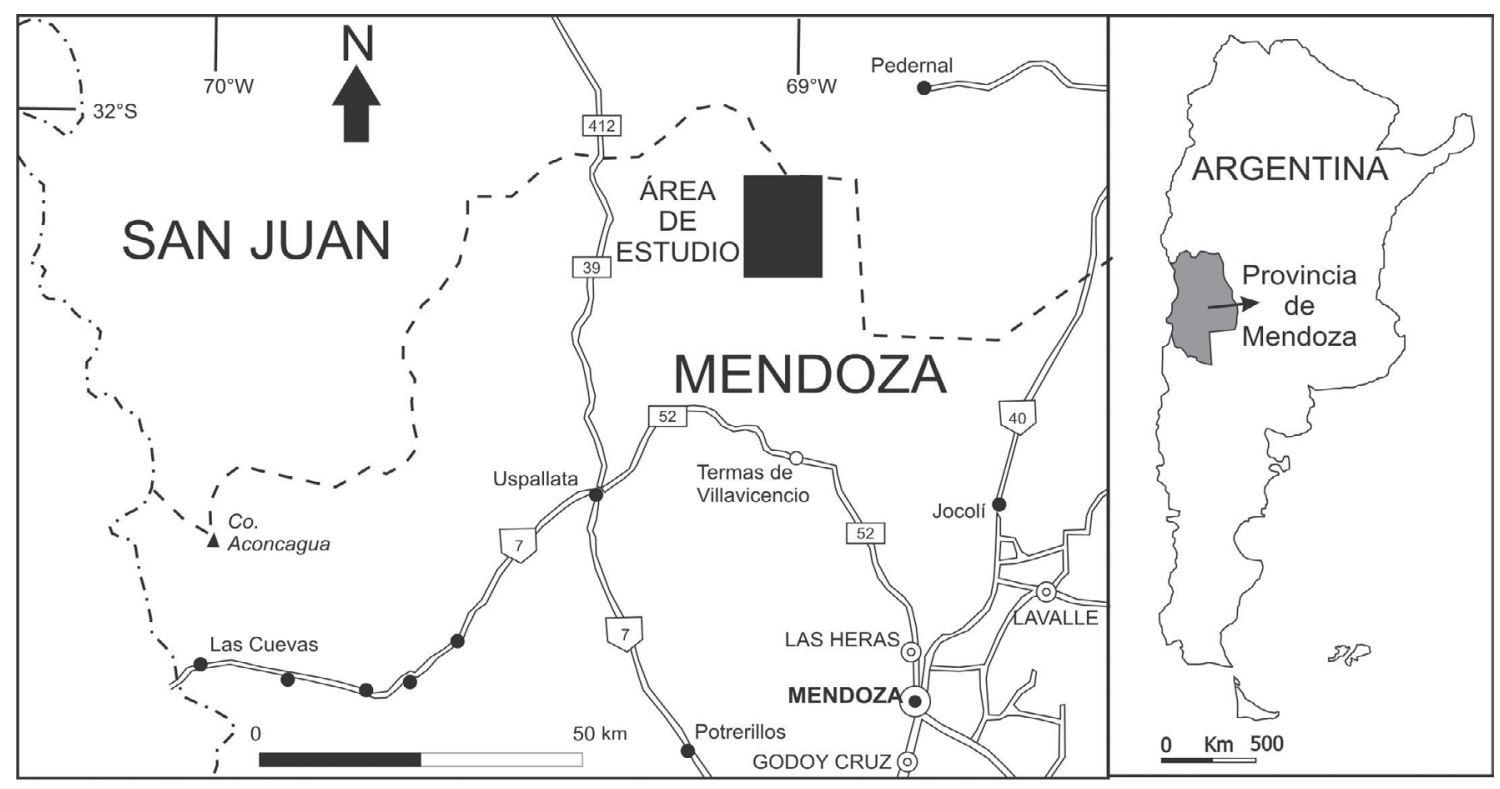

FIG. 1. Mapa de ubicación del área de estudio. 


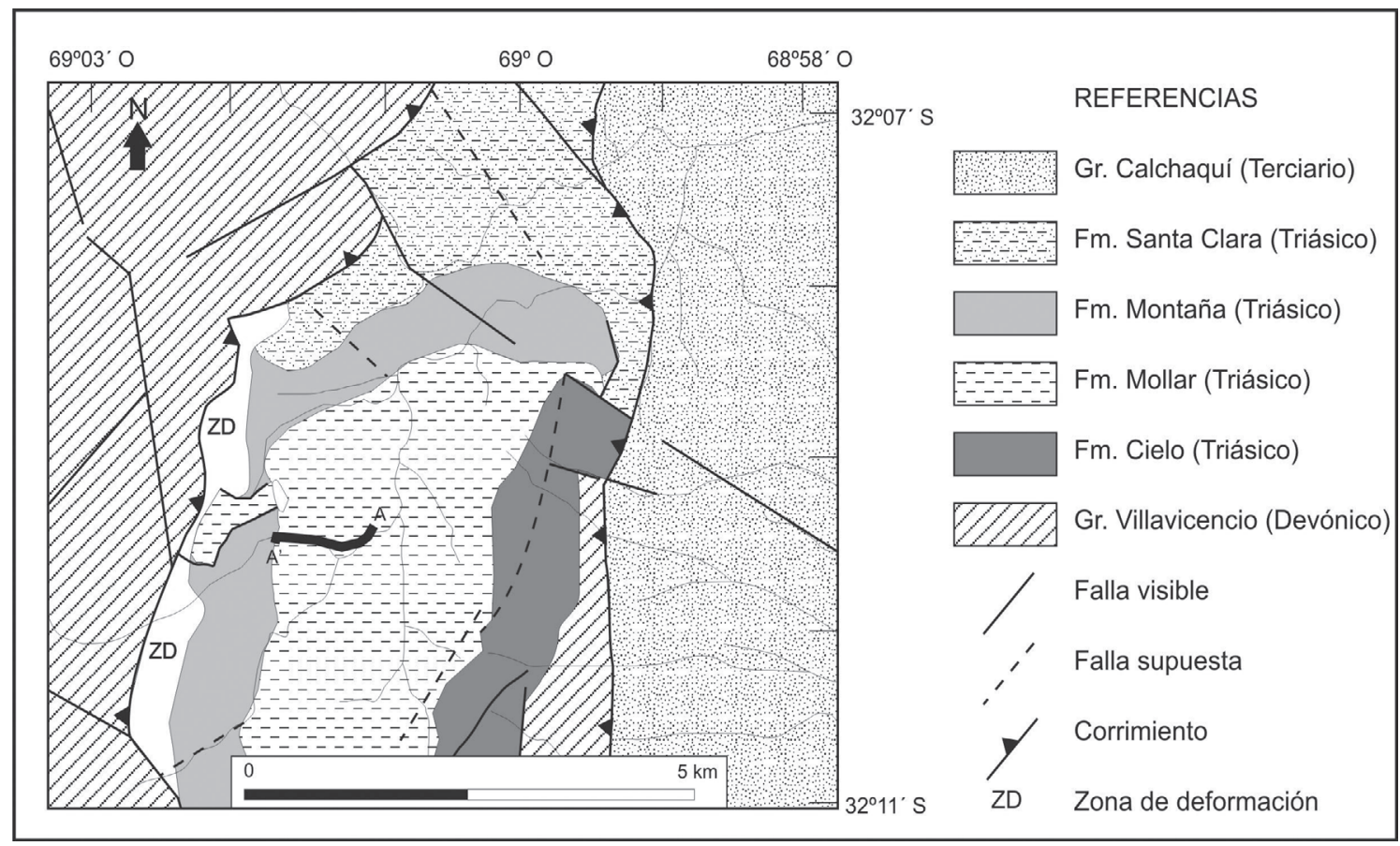

FIG. 2. Mapa geológico del área de estudio. A-A' es la traza del perfil de la Formación Mollar relevado en la Quebrada de la Montaña, depocentro Santa Clara de la Cuenca Cuyana.

netamente fluviales correspondientes a las formaciones Cielo (subyacente) y Montaña (suprayacente). En su mayor parte, y más específicamente en sus 2/3 basales, la Formación Mollar está dominada por lutitas oscuras en sucesiones multiepisódicas ('multistorey') espesas y de gran continuidad lateral (Nesossi, 1945; Yrigoyen y Stover, 1969; Harrington, 1971; Furque y Cuerda, 1979; Bellosi et al., 2001), entre las que se intercalan, en forma subordinada, cuerpos heterolíticos (compuestos por la alternancia de capas de areniscas y fangolitas), y niveles delgados de areniscas muy finas hasta finas macizas y ondulíticas, y de carbonatos estromatolíticos. Hacia arriba, la Formación Mollar muestra un diseño de superposición claramente granocreciente con la aparición de sucesiones heterolíticas y cuerpos de areniscas de textura más gruesa y de mayor espesor, caracterizados por variadas estructuras sedimentarias -tales como capas planas, ondulíticas, entrecruzadas de variado tipo, e incluso frecuentes cuerpos con deformación sinsedimentaria- entre las que se intercalan fangolitas laminadas de tonalidades verdosas y grisáceas.
La Formación Mollar se apoya sobre la Formación Cielo, que consiste en una sucesión de depósitos de conglomerados volcanoclásticos a los que suceden areniscas gruesas y sabulitas rojizas y moradas, en tanto son escasas las intercalaciones de sedimentitas finas; por su textura dominantemente gruesa, estas sedimentitas pueden ser interpretadas como el resultado de la acumulación en sistemas fluviales proximales. Debe señalarse que en el área de estudios, el contacto entre ambas unidades no es depositacional, sino que se manifiesta por fallamiento (Ichazo, 1973, in Cortés et al., 1999). La Formación Mollar es -a su vez- sucedida en forma concordante por depósitos fluviales de la Formación Montaña, constituida esencialmente por areniscas medianas a muy gruesas y sabulitas de tonalidades variadas (rosadas, blanquecinas, hasta rojas y moradas) en cuerpos lenticulares con profusa estratificación entrecruzada, a las que se asocian niveles de pelitas moradas, verdoso pálidas y rojo ladrillo. En esta unidad se han descrito recientemente restos de troncos fósiles (Artabe et al., en prensa) y compresiones e impresiones de restos vegetales de articuladas (Nesossi, 1945). 


\begin{tabular}{|c|c|c|c|}
\hline \multicolumn{2}{|c|}{$\begin{array}{c}\text { UNIDAD } \\
\text { LITOESTRATIGRÁFICA }\end{array}$} & ESPESOR & LITOLOGÍA \\
\hline \multirow{5}{*}{ 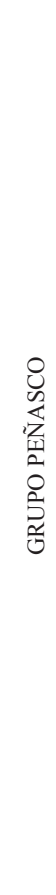 } & $\begin{array}{l}\text { Fm. Santa Clara } \\
\text { Arriba }\end{array}$ & $\sim 250 \mathrm{~m}$ & $\begin{array}{l}\text { Areniscas finas ama- } \\
\text { rillento blanquecinas. } \\
\text { Lutitas, tobas y } \\
\text { limonitas moradas y } \\
\text { verdosas. }\end{array}$ \\
\hline & $\begin{array}{c}\text { Fm. Santa Clara } \\
\text { Abajo }\end{array}$ & $\sim 500 \mathrm{~m}$ & $\begin{array}{l}\text { Lutitas, limonitas, } \\
\text { fangolitas y areniscas } \\
\text { finas gris verdosas y } \\
\text { verdosas. Lentes de } \\
\text { conglomerados. }\end{array}$ \\
\hline & Fm. Montaña & $\sim 500 \mathrm{~m}$ & $\begin{array}{l}\text { Areniscas gruesas y } \\
\text { conglomerados de } \\
\text { colores diversos, junto } \\
\text { a areniscas fangosas y } \\
\text { fangolitas oscuras. }\end{array}$ \\
\hline & Fm. Mollar & $\sim 400 \mathrm{~m}$ & $\begin{array}{l}\text { Lutitas negras, } \\
\text { fangolitas verdosas } \\
\text { y areniscas grises, } \\
\text { amarillentas y } \\
\text { verdosas. }\end{array}$ \\
\hline & Fm. Cielo & $\sim 600 \mathrm{~m}$ & $\begin{array}{l}\text { Conglomerados, } \\
\text { areniscas y limolitas } \\
\text { arenosas de tonos } \\
\text { rojizos y amarillentos. }\end{array}$ \\
\hline
\end{tabular}

FIG. 3. Columna estratigráfica de la sucesión triásica en la región de Santa Clara, Cuenca Cuyana.

\section{Materiales y métodos de estudio}

Las tareas de campo consistieron en el levantamiento a escala de detalle $(1: 100)$ de un perfil sedimentológico en los depósitos de la Formación Mollar, cuya ubicación se muestra en la figura 2. Este perfil, medido a lo largo de la quebrada de la Montaña, permitió reconocer y medir una sección bastante completa, de $345 \mathrm{~m}$ de espesor, aunque sin base expuesta y hasta el contacto superior con la Formación Montaña (Fig. 4). Simultáneamente al relevamiento se efectuó un muestreo sistemático de las sedimentitas, con énfasis en los materiales pelíticos, con el objeto de proceder al estudio palinológico.

El análisis sedimentológico estuvo destinado a la definición de facies, asociaciones de facies y secuencias sedimentarias. El estudio facial con criterio observacional se basó en la caracterización litológica de los estratos (textura y composición), estructuras primarias y arquitectura bidimensional de los cuerpos de roca (cf. Spalletti, 2001b). Cada litofacies fue interpretada en términos de procesos elementales de transporte y depositación. Sobre la base de las vinculaciones espaciales entre las facies sedimentarias, en especial las tendencias en la superposición de distintos cuerpos sedimentarios, se establecieron las asociaciones de facies que permitieron -a su vez- definir los principales sistemas de depositación. Por último, a partir del análisis de conjunto de las asociaciones y la definición de las principales discontinuidades se procedió al análisis secuencial que permitió elaborar conclusiones sobre los controles en el desarrollo del registro sedimentario.

Para el estudio palinológico se procesaron un total de 18 muestras de pelitas negras (Fig. 4) mediante técnicas de laboratorio estándar. Para el estudio de palinofacies se siguieron los métodos descritos por Batten (1982) y Batten y Morrison (1983). Para la determinación del contenido orgánico total de cada nivel (palinofacies), se produjeron dos 'slides' por muestra/nivel. Un primer preparado conteniendo el residuo orgánico sedimentario original producido después del tratamiento estándar con ácidos $\mathrm{HCl}$ HF, sin ningún tipo de tratamiento adicional a fin de hacer una evaluación/valoración visual cualitativa del residuo orgánico sin afectar el color natural de algunos componentes (por ejemplo fragmentos de tejidos o palinomorfos de color amarillo-claro). En el segundo preparado el residuo orgánico restante fue sometido a una breve oxidación (de 2 minutos) con $\mathrm{HNO}_{3}$ concentrado, vibración ultrasónica y tamizado con malla de $10 \mu \mathrm{m}$ (tratamiento OUF) para eliminar parte del abundante material amorfo finamente dividido que predomina en todas las muestras y enmascara el resto de los componentes orgánicos de las palinofacies (Batten y Morrison, 1983). Los recuentos de los constituyentes orgánicos de las distintas palinofacies se realizaron en este segundo preparado, una vez desagregadas las partículas orgánicas aglutinantes (grumos) y luego de haber eliminado parte del material amorfo finamente dividido. El estudio y recuento de los componentes orgánicos de cada muestra se efectuó con microscopio de luz transmitida y se contaron aproximadamente 500 partículas de detritos orgánicos (mayores a $5 \mu \mathrm{m}$ ) y palinomorfos por muestra/preparado utilizando objetivo de $\times 40$. Los recuentos fueron convertidos en porcentajes (Fig. 5). 


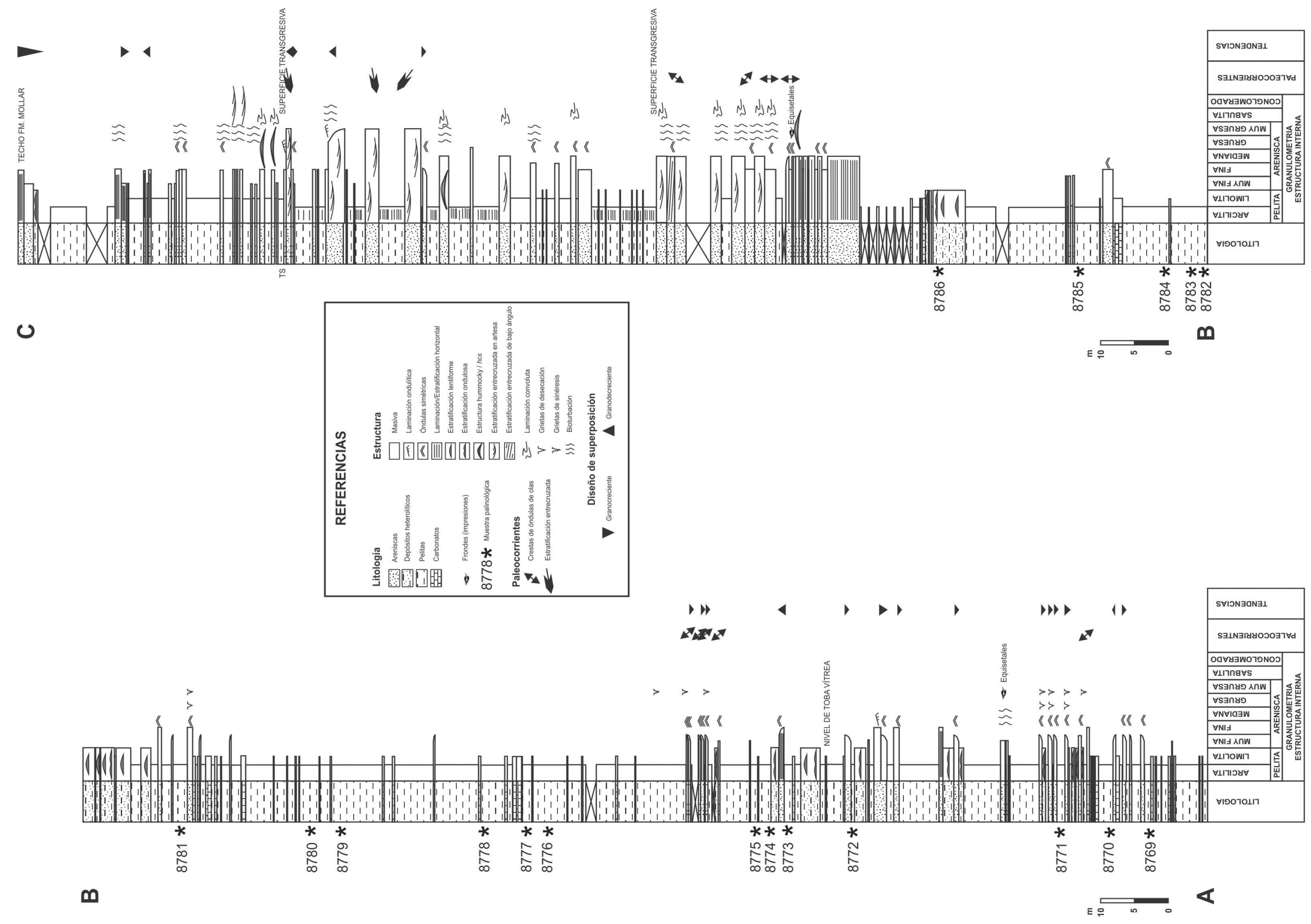


El material estudiado y los ejemplares que se ilustran están identificados con el número de preparado (8769 al 8786, Fig. 4), la sigla MPLP (Mendoza-Paleopalinología-Laboratorio de $\mathrm{Pa}$ leopalinología). Los preparados palinológicos están depositados en la paleopalinoteca del IANIGLA, CCT-CONICET-Mendoza.

\section{Análisis de facies y procesos sedimentarios}

La Formación Mollar se caracteriza por el notable predominio de depósitos silicoclásticos, que varían en textura desde pelitas hasta areniscas y muy esporádicas sabulitas.

La facies de lutitas negras es absolutamente dominante en la mayor parte del registro de la Formación Mollar, y muy en especial en un potente sector inferior de la unidad. Son fangolitas físiles que se presentan en cuerpos que varían en espesor desde unos pocos centímetros hasta más de $10 \mathrm{~m}$ y poseen una notable continuidad lateral, medida en centenares de metros. En las lutitas negras es rara la presencia de fósiles; no obstante, en ellas se han podido identificar restos transportados de artrófitas (Equisetites sp.) de hábitos hidrófilos, típicas de las riberas de los cursos de agua, en las márgenes de los lagos o lagunas y/o en ambientes pantanosos. Estos depósitos lutíticos se interpretan como el producto de la decantación a partir de plumas suspensivas ('overflows' e 'interflows') en un ambiente subácueo de muy baja energía, y condiciones anóxicas en la interfase agua-sedimento (Ghibaudo, 1992; Talbot y Allen, 1996; Spalletti, 1997, 2001b). Por su textura fina, sus estructuras laminares y la preservación de la materia orgánica representan a los depósitos distales ('offshore') de un sistema lacustre hidrológicamente cerrado (Dam et al., 1995) de condiciones meromícticas caracterizado por la estratificación de sus aguas por muy largos períodos (cf. Katz, 1995; Martinek et al., 2006).

En los términos superiores de la Formación Mollar los depósitos atribuidos a ambiente lacustre costa afuera ('offshore') son diferentes. Algunas sucesiones pelíticas de hasta $6 \mathrm{~m}$ de espesor están formadas por lutitas y fangolitas laminadas y macizas, de tonalidades verdosas, que muestran evidencias de bioturbación (estructuras moteadas). Por su textura fina y sus estructuras primarias estos sedimentos reflejan también la depositación en las áreas distales de un sistema lacustre, pero con un bajo contenido de materia orgánica y apreciable valor de la relación hierro ferroso/hierro férrico (Potter et al., 1980; Mack y Stout, 2005), lo que refleja un fondo con pobre oxigenación aunque no de condiciones tan extremas como en el caso de las lutitas negras (cf. Martinek et al., 2006) muy posiblemente debido a cambios en la profundidad de la cubeta, en el nivel del lago e incluso a una mayor mezcla en las aguas más profundas por incremento en la energía de los vientos superficiales. Una alternativa menos probable en el presente caso es que estos depósitos pelíticos puedan haberse acumulado por encima de la termoclina en un cuerpo lacustre en el que en el hipolimnion perduraban las condiciones de sedimentación anóxicas (cf. Melchor, 2007). Los intervalos pelíticos que aparecen hacia la parte superior de la Formación Mollar están dominados por limolitas grisáceas pálidas, macizas, con frecuencia moteadas. Estos depósitos sugieren un cambio en los ambientes de sedimentación hacia condiciones que reflejan incrementos de energía y/o en la textura de los materiales disponibles para la decantación suspensiva, así como altos niveles de oxigenación en la interfase sedimentaria del ambiente lacustre costa afuera. Esto sugiere el desarrollo de un sistema lacustre holomíctico de circulación abierta.

Las areniscas intercaladas en estas sucesiones de grano fino son de textura muy fina a mediana con moderada selección. Se presentan en capas macizas no gradadas hasta normalmente gradadas. Los espesores de las capas van de 5 a $20 \mathrm{~cm}$, pueden ser seguidas lateralmente por varias decenas de metros, y los límites de los estratos son -en general- planos y netos. En la base de estas capas son frecuentes las lineaciones subestratales muy delicadas y de pequeña dimensión producidas por objetos, como calcos de surco ('groove casts'), de punzamiento ('prod casts') y de roce ('bounce casts') que evidencian la acción de corrientes débiles. Algunos de estos depósitos portan restos de plantas. Esta facies se atribuye a corrientes de turbidez de baja densidad en las que se produjo un proceso de depositación muy rápido grano por grano desde una suspensión turbulenta que no permitió el desarrollo de formas de lecho (Lowe, 1982; Smith, 1986; Ghibaudo, 1992; Horton y Schmitt, 1996). Estas corrientes pueden vincularse con flujos friccionales muy distales producidos por ingreso de aguas fluviales así como con el desarrollo de flujos de fondo derivados del oleaje (Spalletti, 1997).

En estrecha asociación con los depósitos de lutitas negras se registra la aparición de niveles 

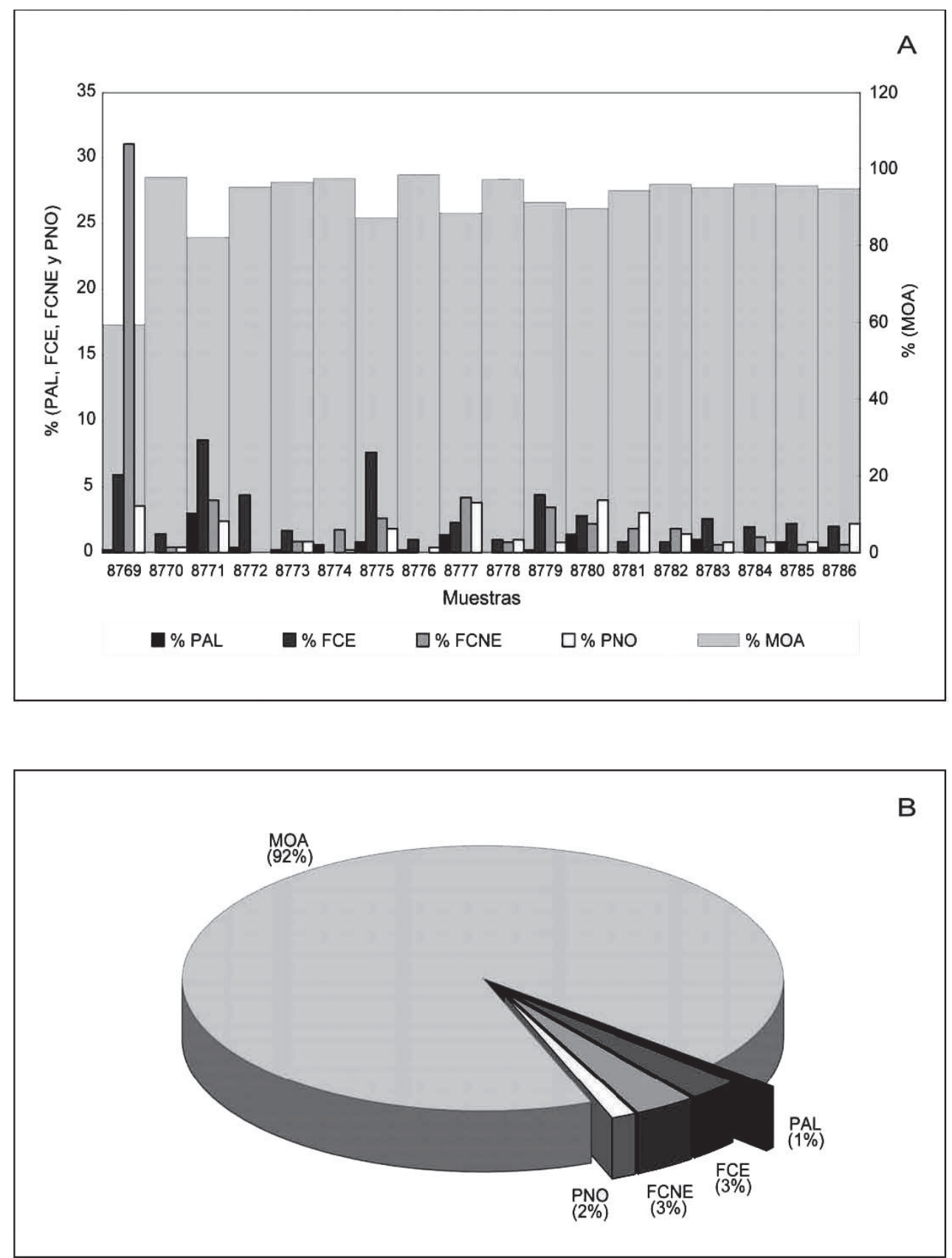

FIG. 5. Frecuencias relativas de la materia orgánica dispersa reconocida en las palinofacies de la Formación Mollar. A. Histograma de distribución porcentual de los grupos orgánicos por muestra/nivel: sobre la izquierda se representan las frecuencias de los componentes con escasa participación, la escala de la derecha representa la proporción de MOA ampliamente dominante; B. Representación de los porcentajes de cada grupo orgánico en la sección estudiada. Las siglas utilizadas están referidas en la Tabla 1.

muy delgados (entre 7 y $12 \mathrm{~cm}$ ) de carbonatos micríticos y margas de tonalidad grises intensas a oscuras. A pesar de su escaso espesor, estas capitas muestran una singular extensión lateral, medida en decenas de metros. Esta facies refleja un cambio en las condiciones de sedimentación en el ambiente de lacustre costa afuera, en el que se mantuvieron las condiciones anóxicas a subóxicas, pero se pro- 
dujo una singular variación en la relación entre los aportes terrígenos y la productividad de material carbonático en el propio cuerpo lacustre (cf. Johnson y Graham, 2004).

En la sección inferior de la Formación Mollar también se registra el desarrollo de otros cuerpos de rocas carbonáticas. Se trata de capas lateralmente continuas, entre 10 y $50 \mathrm{~cm}$ de espesor constituidas por carbonatos de textura fina (micrítica) con laminación delgada (de $1 \mathrm{a} 4 \mathrm{~mm}$ ), de tipo estromatolítica. La estructura interna muestra delicadas corrugaciones subhorizontales hasta hemiesferoides coalescentes en sentido lateral y con discreta convexidad hacia el tope de las capas. En los relevamientos de campo no se han identificado fósiles en estos niveles carbonáticos. Se atribuyen a la precipitación de carbonato como resultado de la captación de $\mathrm{CO}_{2}$ por actividad fotosintética (Eugster y Kelts, 1983; Platt y Wright, 1991) y atrapamiento de material calcáreo finamente diseminado en láminas de algas (Dean y Fouch, 1983). Se considera que la formación de estas estructuras estromatolíticas se produjo en condiciones de oxigenación del ambiente.

En la Formación Mollar son comunes las facies heterolíticas, constituidas por la alternancia de capas delgadas y muy delgadas de fangolitas grises macizas y areniscas castañas con laminación ondulítica y óndulas simétricas hasta ligeramente asimétricas (de flujo combinado) en las que también se registra la presencia de grietas de sinéresis. Sobre la base de las proporciones entre sedimento pelítico y psamítico, se reconocen estructuras ondulosas ('wavy') y lentiformes ('lenticular') (Reinek y Singh, 1980). Estos depósitos pueden ser interpretados como el producto de la sedimentación en un cuerpo de agua con marcadas oscilaciones en la energía, desde decantación suspensiva hasta acción de corrientes orbitales en la interfase sedimentaria.

Las facies de areniscas se diferencian esencialmente por sus estructuras internas: con capa plana o laminación paralela ('plane bed'), laminación ondulítica, 'hummocky cross stratification' ('hcs') y estratificación entrecruzada en artesa. Los depósitos con capa plana se interpretan como el producto de depositación traccional por actividad del oleaje en aguas poco profundas (Reineck y Singh, 1980; Casshyap y Aslam, 1992); en estos niveles aparecen grietas de sinéresis y/o de desecación en los planos de estratificación. Los cuerpos con laminación ondulítica muestran -al igual que en la facies hete- rolítica- la agradación de óndulas simétricas hasta ligeramente asimétricas; su geometría, longitud de onda y amplitud sugieren la actividad de olas orbitales y traslacionales en aguas poco profundas, y su escalonamiento un importante aporte de sedimento (Horton y Schmitt, 1996). Las areniscas con estructura monticular o 'humocky' son el testimonio de la actividad de olas oscilatorias de tormenta (Eyles y Clark, 1986; Martel y Gibbling, 1991; Spalletti, 1997). Por su parte, las areniscas con estratificación entrecruzada en artesa son el resultado de la migración de dunas o barras subácueas en condiciones de régimen de flujo bajo (cf. Horton y Schmitt, 1996).

\section{Asociaciones de facies y ambientes de depo- sitación}

El estudio de la vinculación vertical entre los distintos cuerpos de roca de la Formación Mollar nos ha permitido definir dos asociaciones de facies: lacustres costa afuera ('offshore') y lacustres marginales.

\subsection{Asociaciones lacustres costa afuera ('offshore') y de la transición 'nearshore'-'offshore'}

En el registro sedimentario de la unidad estudiada se aprecia una singular variación en las características de las asociaciones de facies correspondientes a los ambientes lacustres más distales (Fig. 4).

Así, las potentes sucesiones de grano fino que son típicas de la sección inferior muestran una asociación en la que dominan totalmente las lutitas negras (Fig. 4) junto a muy delgadas intercalaciones de calizas micríticas y margas oscuras que -en conjunto- reflejan una sedimentación por decantación suspensiva en condiciones hipolímnicas, típicas de los sectores distales de un lago con aguas profundas, estratificadas y fondo anóxico (Talbot y Allen, 1996; Carroll y Bohacs, 2001). Junto a ellas aparecen en forma no sistemática capas delgadas de turbiditas de baja densidad que hemos atribuido a flujos friccionales de baja energía procedentes de áreas someras y marginales, ya que algunas portan restos plantíferos de artrófitas equisetales.

Se asocian a estas espesas secciones, cuerpos sedimentarios que ponen en evidencia procesos de somerización y por ende el pasaje a regiones de transición 'nearshore'-'offshore'. Por una parte 
aparecen las capas de carbonatos micríticos con estructuras estromatolíticas (Fig. 4), formadas en condiciones de mayor oxigenación del sustrato, en condiciones epilímnicas, y que sugieren una variación en el nivel de las aguas lacustres y la muy probable migración de la línea de costa (Dam y Surlyk, 1993). Por otra, cuerpos de areniscas muy finas a finas con diseño de superposición granocreciente compuestos en su base (a veces) por un nivel heterolítico y luego por una capa de areniscas con agradación de óndulas de olas, la que puede culminar con un nivel algo más grueso con estructura de capa plana y grietas, posiblemente de sinéresis, al tope. Estos cuerpos no son muy potentes (entre 0,30 y $1,50 \mathrm{~m}$, Fig. 4) pero poseen geometría tabular y una considerable continuidad lateral, de varias decenas de metros. Por su diseño de superposición y las facies que los conforman estos litotomas pueden ser considerados PACs ('punctuated aggradational cycles', Goodwin y Anderson, 1985; Goodwin et al., 1986), es decir, ciclos granocrecientes de somerización limitados en su tope por una superficie transgresiva que en el caso de la Formación Mollar suele estar representada por un nivel de lutitas negras (muy organógenas). La presencia de este depósito sugiere un evento en el que se produjo importante reducción en la tasa de sedimentación. La formación de estos niveles condensados se puede explicar como la respuesta sedimentaria a un ascenso en el nivel del lago.

Un tercer tipo de depósito de la región de transición entre 'nearshore' y 'offshore' lacustre es el de pares heterolíticos definidos por una persistente alternancia entre capas fangolíticas y capas de areniscas muy finas y finas con frecuentes óndulas orbitales y laminaciones ondulíticas. Estos sedimentos son debidos a cambios rítmicos en la dinámica del sistema lacustre, es decir en una posición cercana a la base del tren de olas o bien a profundidades algo mayores en las que en condiciones normales se da la decantación suspensiva y en períodos de tormenta se registra la interacción del tren de olas con el sustrato (cf. Marshall, 2000). Como sugirieran Rajchl et al. (2008), los depósitos heterolíticos pueden ser el producto de la acumulación en áreas de prodelta.

Las asociaciones de facies de ambiente lacustre costa afuera que se observan en los tramos superiores de la Formación Mollar (Fig. 4) son bastante diferentes. Ellas consisten esencialmente en depósitos de lutitas y fangolitas laminadas de tonalidad verdosa pálida a oscura, y limolitas de color gris pálido, macizas y profusamente bioturbadas, con frecuente moteado (Fig. 4). Estas facies reflejan un grado de oxigenación variable en el fondo lacustre, desde condiciones subóxicas hasta francamente óxicas, lo que permite sugerir su acumulación en un sistema lacustre holomíctico, hidrológicamente abierto. A estas sedimentitas de grano fino se asocian intercalaciones aisladas de areniscas medianas a finas en estratos no gradados y gradados, siempre con su base irregular, y con presencia de lineaciones y deformaciones subestratales. Estas areniscas se atribuyen a flujos friccionales o hiperpicnales inducidos por aportes fluviodeltaicos o por tormentas.

\subsection{Asociaciones lacustres marginales}

Se caracterizan por la presencia de facies de areniscas que -por sus estructuras primarias (óndulas de olas y de flujo combinado, estructuras entrecruzadas y de laminación paralela)- se interpretan como depósitos de aguas someras donde el sustrato ha estado sometido a la acción de corrientes orbitales a unidireccionales de variada energía.

Los depósitos constituidos esencialmente por la amalgamación de capas de areniscas se ordenan en tres tipos de secuencias elementales: multiepisódicas, granocrecientes y granodecrecientes (Fig. 4). En todas estas situaciones, las areniscas muestran evidencias de importante bioturbación, y son comunes las trazas fósiles intraestratales (endichnia) y estratales (epichnia), como Skolithos, Arenicolites, Diplocraterion, Cruziana y Planolites. Los cuerpos con dominio de arena tienen un muy marcado desarrollo en los términos medios a altos del registro de la Formación Mollar, lo que -junto con la aparición de facies de costa afuera ('offshore') atribuidas a sistemas lacustres abiertos- sugiere una tendencia general a la sedimentación en condiciones lacustres someras, más marcadas variaciones en la paleobatimetría de los sistemas y un progresivo decrecimiento en la acomodación sedimentaria.

Los cuerpos multiepisódicos, de hasta $9 \mathrm{~m}$ de potencia, se definen por la superposición de estratos de areniscas finas hasta medianas que pueden estar constituidos por un único tipo de estructura primaria o por capas con diversas estructuras (laminaciones ondulíticas, estructura monticular o 'hcs', capas planas, estratificación entrecruzada). Son el resultado de un proceso de agradación con acumulación persistente de arenas aportadas desde las zonas 
marginales y retrabajadas en el ambiente lacustre marginal por la acción de corrientes de variado régimen vinculadas tanto con el oleaje como con corrientes unidireccionales.

Los cuerpos granocrecientes, con espesores entre 1 y $4 \mathrm{~m}$, pueden mostrar estructura interna masiva, estar constituidos enteramente por laminación ondulítica de olas, o por la superposición de un intervalo inferior ondulítico y otro superior con capa plana de alto régimen de flujo hasta con estructura monticular. En la parte superior de estos cuerpos pueden encontrarse estratos entrecruzados en artesa. En ellos son frecuentes las deformaciones sinsedimentarias manifestadas por el replegamiento de las estructuras ondulíticas y entrecruzadas e incluso de los planos de estratificación. Las sucesiones granocrecientes de ambientes lacustres pueden ser interpretadas de diversas maneras: como depósitos de frente y plataforma deltaica, de deltas de 'crevasse', de lóbulos deltaicos menores y como depósitos de 'nearshore' de ambiente lacustre abierto (cf. Melchor, 2007). La notable continuidad lateral de estos cuerpos, la alta participación de arena en estratos amalgamados sin particiones pelíticas y el predominio de estructuras generadas por acción del oleaje sugieren que se deben a la progradación de depósitos de lacustres someros ('nearshore') de alta energía y/o de barras de frente deltaico dominadas por la acción de las olas sobre depósitos de costa afuera ('offshore') y de la transición 'nearshore''offshore' (Orton y Reading, 1993; Martinek et al., 2006; Rajchl et al., 2008). La abundancia de las deformaciones sinsedimentarias se asigna al escape de fluidos y constituye evidencia de importantes aportes fluviales de material detrítico hacia la cuenca lacustre, de un alto ritmo de agradación sedimentaria y de procesos de saturación en el interior de las capas de arena.

Por su parte, los cuerpos granodecrecientes son muy comunes en el tramo superior de la Formación Mollar (Fig. 4). Se apoyan sobre un fuerte contacto erosivo, tienen espesores entre 1 y $3 \mathrm{~m}$, y se organizan en un intervalo inferior de grano grueso con capa plana y otro superior mediano-fino con laminación ondulítica. Son asimismo característicos los litosomas dominados por estratos multiepisódicos con estratificación entrecruzada en artesa. Estos depósitos, que también aparecen afectados por procesos de deformación sindeposicional, se interpretan como el relleno de canales fluviales o fluvio-inducidos. Dado el contexto en el que se ha producido su desarrollo se pueden atribuir a canales distributarios de un sistema deltaico (Coleman y Wright, 1975; Chan y Dott, 1986; Elliott, 1986; Spalletti, 2001b) o a canales sublacustres formados por flujos friccionales o hiperpicnales localizados (Reading y Collinson, 1996). El desarrollo de estos depósitos del tope de la Formación Mollar preanuncia el abandono definitivo del sistema lacustre, el que es reemplazado por un conjunto de sedimentitas correspondientes a un sistema fluvial de carga mixta que caracterizan a la Formación Montaña (Bellosi et al., 2001; Artabe et al., en prensa).

\section{Análisis palinológico}

\subsection{Identificación del material palinológico}

En la literatura se cuenta con muchos esquemas de clasificación de la materia orgánica dispersa (cf. Boulter y Riddick, 1986; Van Bergen et al., 1990; Tyson, 1995; Batten, 1996; Oboh-Ikuenobe et al., 1997). En este estudio se utiliza un sistema simplificado adaptado a los tipos de componentes orgánicos presentes, basado en una terminología adaptada de Van Bergen et al. (1990), Batten (1996) y Oboh-Ikuenobe et al. (1997, 2005). Cinco tipos de materia orgánica dispersa se pueden identificar en las muestras analizadas de la Formación Mollar (Fig. 4). En la tabla 1 se definen los componentes orgánicos que componen las palinofacies estudiadas, los que incluyen palinomorfos (PAL), fitoclastos estructurados (FCE), fitoclastos no estructurados (FCNE), partículas negras opacas (PNO) y materia orgánica amorfa (MOA). Esta última puede ser referida solamente como 'sapropel amorfo', aunque su composición puede ser de origen sapropélico a húmico (Tabla 2). La materia orgánica amorfa reconocida en este estudio está formada por material algal altamente degradado (con elevada fluorescencia) y/o deriva también de restos de plantas vasculares y se encuentra también altamente degradada (variedades que no fluorecen o fluorecen escasamente) (ver discusión más adelante).

Los valores que se ilustran en la figura 5a-b representan las frecuencias relativas de los constituyentes orgánicos y de su distribución en el perfil estudiado. 
TABLA 1. DESCRIPCIÓN DE LOS PALINOMORFOS Y COMPONENTES ORGÁNICOS DISPERSOS IDENTIFICADOS EN ESTE ESTUDIO.

\begin{tabular}{ll}
\hline Palinomorfos y detritos orgánicos & Descripción y rasgos principales \\
\hline $\begin{array}{l}\text { PALINOMORFOS } \\
\text { (PAL) }\end{array}$ & $\begin{array}{l}\text { Esporas y granos de polen de plantas vasculares, esporas de hongos, algas (restos) de } \\
\text { agua dulce (Figs 7A, H, J, K). } \\
\text { Restos estructurados de plantas vasculares que incluyen partículas con formas bien defini- } \\
\text { das, restos de parénquima y fragmentos de cutículas, fragmentos de tejidos con estructura } \\
\text { celular (no cuticular o leñoso), fragmentos de fitoclastos con algún tipo de estructuras } \\
\text { celular, tubos, filamentos (Figs 7B, G, I, K, N, O). }\end{array}$ \\
$\begin{array}{l}\text { FITOCLASTOS ESTRUCTURADOS } \\
\text { FCE) }\end{array}$ & $\begin{array}{l}\text { Fragmentos de color marrón oscuro a casi negro, generalmente de forma angular a rectan- } \\
\text { gular de variable tamaño, derivado de restos leñosos altamente degradados (sin estructu- } \\
\text { ras orgánicas visibles) (Figs 6E, J). Partículas de resinas de color amarillo, anaranjado y } \\
\text { transparente, de aspecto globular, con superficies con fractura concoidal (Fig 7M). }\end{array}$ \\
$\begin{array}{l}\text { FITOCLASTOS NO ESTRUCTURADOS } \\
\text { (FCNE) }\end{array}$ & $\begin{array}{l}\text { Partículas totalmente opacas, generalmente tienen forma poligonal (rectangular a trian- } \\
\text { gular), en general de pequeño tamaño derivadas de restos leñosos altamente oxidados } \\
\text { (inertinita + vitrinita) (Figs 7A, C). }\end{array}$ \\
$\begin{array}{l}\text { PARTÍCULAS NEGRAS OPACAS } \\
\text { (PNO) }\end{array}$ & $\begin{array}{l}\text { Materia orgánica no estructurada formada por masas de variable textura (fibrosa, gru- } \\
\text { mosa, granular, etc.), generalmente de color amarillo pálido, amarillo oscuro, marrón y } \\
\text { marrón-negro (Figs 6 A-L). }\end{array}$ \\
\hline $\begin{array}{l}\text { MATERIA ORGÁNICA AMORFA } \\
\text { (MOA) }\end{array}$ &
\end{tabular}

TABLA 2. TIPOS DE MACERALES, ORIGEN, SIGNIFICADO Y POTENCIAL HIDROCARBURÍFERO.

\begin{tabular}{|c|c|c|c|c|c|}
\hline $\begin{array}{l}\text { Potencial de } \\
\text { hidrocarburos }\end{array}$ & \multicolumn{3}{|c|}{$\begin{array}{c}\text { Petrografía orgánica } \\
\text { (terminología) }\end{array}$} & $\begin{array}{c}\text { Pirólisis } \\
\text { Tipo de kerógeno } \\
\text { (indice de } \mathbf{H} / \mathbf{O} \text { ) }\end{array}$ & $\begin{array}{c}\text { Origen } \\
\text { (no implica ambiente deposicional) }\end{array}$ \\
\hline \multirow[t]{2}{*}{$\begin{array}{c}\text { Petróleo } \\
\text { propenso } \\
\text { (en menor proporción } \\
\text { condensados o gas) }\end{array}$} & Exinita & $\begin{array}{c}\text { Algal/ } \\
\text { Material } \\
\text { amorfo } \\
\text { (sapropel) } \\
\text { Herbáceo }\end{array}$ & Firógeno & Tipo II & $\begin{array}{l}\text { Acuático: } \\
\text { Algas (de agua dulce o marinas) } \\
\text { que por degradación bacteriana } \\
\text { resultan en material amorfo. } \\
\text { Material terrestre (esporas, polen, } \\
\text { cutículas o resina) total o parcial- } \\
\text { mente degradado. }\end{array}$ \\
\hline & Vitrinita & Leñoso & Hialógeno & Tipo III & $\begin{array}{l}\text { Terrestre: } \\
\text { Tejidos ligno-celulósicos poco } \\
\text { alterados, en forma de partículas } \\
\text { (fitoclastos) y material amorfo. }\end{array}$ \\
\hline $\begin{array}{c}\text { Inerte } \\
\text { (carbón muerto) }\end{array}$ & Inertinita & Carbón & Melanógeno & Tipo IV & $\begin{array}{l}\text { Terrestre: Tipo I } \\
\text { Tejidos ligno-celulósicos alterados } \\
\text { por oxidación en el suelo, por trans- } \\
\text { porte, por fuegos forestales, etc. }\end{array}$ \\
\hline
\end{tabular}

\subsection{Palinofacies}

Las facies lacustres, dominadas por lutitas negras, que se registran en la sección inferior a media del perfil de la quebrada de la Montaña (Fig. 4) contienen abundante materia orgánica altamente degradada (cuyos rangos oscilan entre el 59\% y más del 97\% del total de componentes orgánicos por nivel) cuyo origen proviene del aporte terrestre -restos de plantas vasculares- como de origen acuático -componentes algales-. La discriminación cuantitativa de la procedencia de la materia orgánica amorfa se realiza generalmente utilizando luz fluorescente y análisis geoquímicos. No obstante, es posible determinar su origen mediante la observación microscópica.

Las palinofacies más representativas identificadas en este estudio se ilustran en la lámina 1, en tanto que los tipos de materia orgánica amorfa y sus principales componentes están representados en las láminas 2 y 3 , respectivamente. 
La materia orgánica amorfa de origen vegetal proviene de miosporas (e.g., Láms. 2G; 3J y L), cutículas (e.g., Lám. 3G) y otros tejidos de plantas vasculares (e.g., Láms. 2C; $3 \mathrm{~K}$ y $\mathrm{H}$ ), fitoclastos ligno-celulósicos (e.g., Láms. 2K y L; 3A y B) o de una mezcla de ellos. Cuando la degradación y la reducción en finas fracciones (material finamente dividido) de estos restos han sido considerables, es aún posible determinar sus afinidades por la presencia de restos no alterados completamente (e.g., Láms. 2K y L; 3G, N, O), ya que en ellos se alcanzan a observar variadas formas y estructuras orgánicas originales de estos componentes. Evidencias de algunos de los organismos responsables de los procesos de degradación de estos constituyentes se pueden manifestar por la presencia de hifas y esporas de hongos en los fitoclastos, cristales de pirita o sus estructuras relictuales (e.g., Láms. 2D y G; 3J, L, $\mathrm{N}, \mathrm{O}$ ), microperforaciones (granulación) (e.g., Lám. 2D, C, L) y/o por adelgazamiento y obliteración de las exinas de los palinomorfos y de otros detritos orgánicos (e.g., Lám. $2 \mathrm{H}$ y N). La abundancia de pirita puede ser interpretada como el producto de la actividad de bacterias sulfuro-reductoras, en tanto que la microgranulación y adelgazamiento de los palinomorfos está también indicando actividad microbiana (Batten, 1973; 1979). En estas palinofacies la MOA finamente dividida es de color castaño oscuro y se compone además de masas o agregados de variable tamaño de color marrón hasta negro, formadas por material altamente degradado de aspecto granular, esponjoso a fibroso, y restos de tejidos o de fitoclastos degradados diferencialmente. Son asimismo escasos los fitoclastos estructurados y no estructurados y los pequeños fragmentos oxidados opacos, además de escasos palinomorfos (esporas y bisacados muy degradados, corroídos y piritizados, casi irreconocibles) (Lám. 3A, J, L). En la lámina $1 \mathrm{C}-\mathrm{F}$ se ilustran palinofacies dominadas por material amorfo con alto porcentaje de material vegetal altamente degradado; sus caracteres se describen en los epígrafes correspondientes.

La materia orgánica amorfa de origen algal está dominada también por material amorfo finamente dividido (partículas $<5 \mu \mathrm{m}$ ) de color amarillo pálido (translúcidas) o castaño claro a marrón-gris y por detritos minerales aglutinados (de aspecto coloidal o subcoloidal) (Lám. 1A-B, G-H) además de pequeñas masas sólidas o grumos formados por este material amorfo que da un aspecto granular (Lám. $1 \mathrm{G}-\mathrm{I})$. Los agregados de partículas de textura granu- lar que prevalecen en el segundo preparado (Lám. $1 \mathrm{G}-\mathrm{H})$ se interpretan como producto de la acumulación de material algal altamente degradado. Batten (1982, 1999) y Villar et al. (1991) comprobaron que la resistencia de parte de este material a ser eliminado por los tratamientos de oxidación, vibración ultrasónica y filtrado (OUF) permite interpretar su origen y su estadio de madurez. Batten (1982) y Batten y Morrison (1983) comprobaron que el material finamente dividido derivado de plantas vasculares se desintegra y se elimina más fácilmente por estos procedimientos que el de origen acuático (Lám. 1A-B, E-F). Llamativamente, se han observado muy escasos restos de algas clorófitas (como Botryococcus) en estas palinofacies, lo que puede deberse al estado avanzado de degradación, a las condiciones físico-químicas del medio o a los procesos tafonómicos. Al respecto, Batten (1999) señaló que grandes cantidades de material amorfo son indicativas de condiciones principalmente anóxicas, aunque la degradación inicial puede tener lugar, en particular, por la actividad de hongos, bacterias e invertebrados en ambientes acuáticos aeróbicos y eventualmente terrestres.

De acuerdo a su origen biológico, los constituyentes orgánicos pueden ser clasificados en: fragmentos continentales (vitrinita, inertinita, esporomorfos, fitoclastos, tejidos, etc.) que constituyen la fracción alóctona, mientras que los constituyentes 'acuáticos' representan la fracción 'semiautoctona' (algas y materia orgánica amorfa) (Tribovillard y Gorin, 1991) (Tabla 2). Estos componentes orgánicos se comportan como partículas sedimentarias y su distribución areal también se ve afectada por procesos de selección hidrodinámica ligados a la energía depositacional (Fisher, 1980; Whitaker, 1984; Boulter y Riddick, 1986; Tyson, 1987; Van der Zwan, 1990). Las facies orgánicas de un sedimento son también una función del nivel de oxígeno del ambiente, ya que la materia orgánica (excepto la inertinita) es rápidamente biodegradada por bacterias y hongos en ambientes óxicos (Hart, 1986). El grado de biodegradación depende esencialmente del contenido de oxígeno y de la tasa de sedimentación del ambiente de depositación (Hart, 1986; Tyson, 1987). La MOA (a veces llamada materia orgánica no estructurada; Van der Zwan, 1990) es abundante en lagos cuyos sedimentos fueron acumulados en condiciones de baja energía. Posiblemente la depositación de la materia orgánica en los sedimentos lacustres anóxicos de la sección inferior 
de la Formación Mollar se produjo por decantación de material parcialmente degradado, junto con las partículas más finas, formando bancos masivos a ligeramente laminados que la contienen.

\section{Sistemas de acumulación: modelos conceptua- les y evolución}

En el perfil de la quebrada de la Montaña, que es el más completo de la Formación Mollar, se pueden reconocer tres sucesiones correspondientes a ambiente lacustre. Estas sucesiones muestran distinto desarrollo vertical: la inferior alcanza $248 \mathrm{~m}$ sin que esté su base expuesta, la media tiene $58 \mathrm{~m}$ y la superior solamente $39 \mathrm{~m}$ (Fig. 4).

\subsection{EI sistema lacustre hidrológicamente cerrado de la sección inferior a media de la Forma- ción Mollar}

En el potente registro del tramo inferior de la Formación Mollar, la depositación ocurrió esencialmente en ambiente de costa afuera o distal bajo condiciones hipolímnicas anóxicas debidas al desarrollo de un cuerpo lacustre con circulación muy restringida, baja energía dinámica (decantación suspensiva y esporádicas corrientes de densidad diluidas) y alta productividad orgánica, con importante acumulación de materia orgánica degradada a parcialmente degradada, tanto autóctona (algal) como alóctona (vegetal terrestre). Las grietas de sinéresis y la precipitación de niveles de carbonatos permiten sugerir condiciones de discreta salinidad (Collinson y Thompson, 1989), por lo que la meromixis pudo haber estado relacionada con contrastes en el tenor de sales con la profundidad. En forma intermitente se produjeron procesos de acumulación en condiciones epilímnicas, tanto de sedimentos no terrígenos (carbonatos estromatolíticos) como terrígenos manifestados por el pasaje desde niveles heterolíticos a psamíticos con óndulas de olas y capas planas. Como puede apreciarse en la figura 4 , este sistema lacustre culmina con un importante registro de areniscas con diversas estructuras primarias (capas planas de alto régimen, estratificación 'hcs', óndulas de olas y capas entrecruzadas) formadas esencialmente bajo la actividad de olas en las porciones más someras del ambiente lacustre.

Los ciclos sedimentarios asimétricos de alta frecuencia identificados en este sistema lacustre tienen escala pequeña $(0,3$ a $1,5 \mathrm{~m})$ y muestran el progresivo pasaje desde facies de lutitas negras formadas en condiciones hipolíminicas anóxicas a facies heterolíticas y psamíticas epilímnicas con diseño de superposición granocreciente, que reflejan un aumento en los procesos de remoción del sustrato por corrientes orbitales. En su tope están limitados por una superficie neta ('lacustrine flooding surface' en el sentido de Bohacs, 1998) sobre la que aparece un nivel de lutitas muy oscuras (organógenas) que se interpreta como un nivel condensado. Estos ciclos pueden ser atribuidos a cambios en los procesos de expansión y retracción lacustre (cf. Pietras y Carroll, 2006). El diseño de superposición permite interpretar que el fenómeno de retracción de la línea de costa fue bastante progresivo, en tanto que el ascenso subsiguiente fue muy brusco y generó las condiciones para una importante condensación en el registro sedimentario. La presencia de estos ciclos muestra que el sistema lacustre fue altamente susceptible a fluctuaciones hidrológicas de alta frecuencia (cf. Carroll y Bohacs, 1999). Aun cuando en la literatura es común la asignación de estos ciclos a cambios en insolación relacionados con variaciones orbitales (ciclos de Milankovitch; cf. Goodwin y Anderson, 1985), más recientemente Pietras y Carroll (2006) han llamado la atención sobre su posible desarrollo autogenético como producto de la inestabilidad geomorfológica que la cuenca de drenaje relacionada con el ambiente lacustre.

\subsection{Los sistemas lacustres hidrológicamente abiertos de la sección superior de la For- mación Mollar}

Los dos sistemas lacustres que se definen en la parte superior de la Formación Mollar son singularmente distintos del inferior. Las principales diferencias estriban en la menor escala de las sucesiones, las características de los depósitos pelíticos distales (de 'offshore') y la mucho mayor abundancia de depósitos de areniscas generados bajo la acción de agentes traccionales, tanto vinculados con el oleaje como con corrientes unidireccionales (Fig. 4). En conjunto, estos atributos permiten sugerir una singular merma en el espacio de acomodación sedimentaria, el desarrollo de un ambiente holomíctico de circulación abierta (lago profundo subóxico hasta óxico), mayores variaciones en la posición de los niveles lacustres manifestadas por la interestratificación de depósitos lacustres más distales con otros marginales, frecuentes fenómenos de progradación en los 
depósitos lacustres marginales, y aparición de depósitos de relleno de canales fluviales ofluvio-inducidos los que, asociados a importantes fenómenos de deformación sinsedimentaria, pueden atribuirse a la existencia de cuerpos deltaicos.

\subsection{Sistemas lacustres y ciclicidad}

Los tres sistemas lacustres que se definen en el registro sedimentario de la Formación Mollar revelan el desarrollo de tres ciclos asimétricos de gran escala o de baja frecuencia que muestran el pasaje temporal desde depósitos lacustres de costa afuera a depósitos lacustres marginales (Fig. 6). La base de los mismos está representada por una superficie transgresiva, mientras que la ubicación de una zona de 'máxima inundación' permite definir, a su vez tractos o cortejos transgresivos (TST) y de nivel alto (HST), estos últimos caracterizados por un típico diseño de superposición granocreciente (Fig. 6). La continuidad regional de los depósitos lacustres permite sugerir que estos ciclos están relacionados con episodios de expansión y contracción lacustre acaecidos a nivel de cuenca (Johnson y Graham, 2004). En tal contexto, las variaciones cíclicas que muestran verticalmente las asociaciones de facies depocentrales lacustres y la ausencia de depósitos de granulometría gruesa, ponen en evidencia que uno de los controles en estos fenómenos de expansión-contracción pudo haber sido el clima. Al respecto, Olsen (1990) ha mostrado que importantes cambios en los niveles de las aguas lacustres son la respuesta a variaciones en las precipitaciones producidas por ciclos de oscilación climática inducidos por factores orbitales, esto es en la banda de Milankovitch. No obstante, debe también señalarse que los cambios que se aprecian en la escala de los ciclos y en la creciente participación de depósitos lacustres someros en sentido vertical (Fig. 6) reflejan importantes diferencias de acomodación (Rajchl et al., 2008) que pueden atribuirse a variaciones en la subsidencia, con un máximo de creación de espacio en los términos más bajos del registro de la Formación Mollar.

Por otra parte, el diseño de superposición general que muestra la Formación Mollar pone en evidencia el desarrollo de una megasecuencia asimétrica (Fig. 6), definida por un arreglo general de tipo granocreciente definido por el pasaje desde sistemas lacustres profundos hidrológicamente cerrados a otros menos profundos e hidrológica-

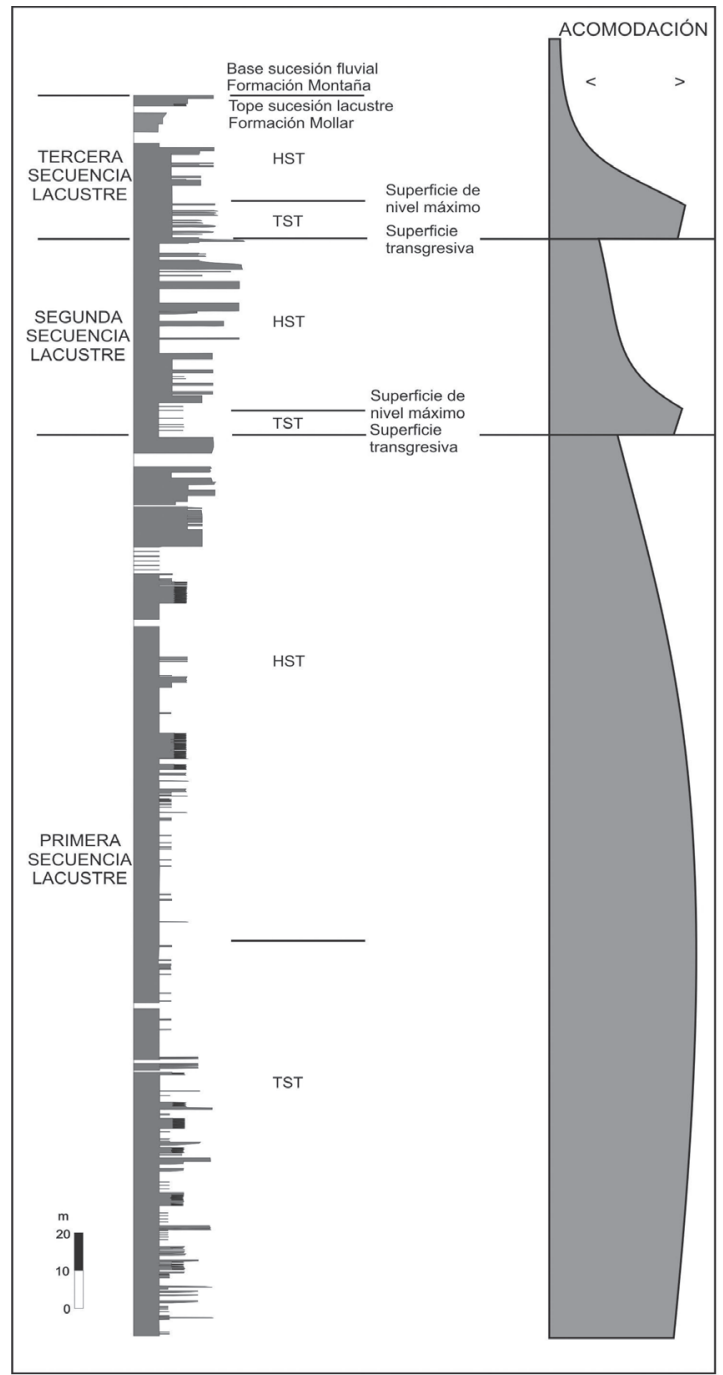

FIG. 6. Diseño de superposición general de la Formación Mollar que muestra la disminución progresiva de acomodación y ciclos sedimentarios asimétricos de baja frecuencia limitados por superficies transgresivas que permiten definir la superposición de tres sistemas lacustres. Nótese que del mismo modo como ocurre en otros sistemas lacustres triásicos de Gondwana occidental (cf. Spalletti, 1997, 2001b; Bellosi et al., 2001) el primero de estos ciclos, con dominio de depósitos generados en condiciones anóxicas, posee máximo desarrollo. TST: tracto o cortejo transgresivo ('transgressive systems tract'); HST: tracto o cortejo de nivel alto ('highstand systems tract').

mente abiertos con progresivo dominio de facies sedimentarias gruesas que finalmente culminan con la implantación de sistemas de neto carácter fluvial (asignables a la Formación Montaña). Esta megasecuencia refleja una constante reducción del 
espacio de acomodación sedimentaria (Fig. 6) que se atribuye a un progresivo decrecimiento en el ritmo de subsidencia mecánica, muy posiblemente como respuesta al pasaje de un estado de 'sinrift' a otro de 'postrift' en el depocentro de Santa Clara.

\section{Conclusiones}

- El presente estudio ha permitido determinar que la potente sucesión correspondiente al tramo inferior y medio de la Formación Mollar está dominada por depósitos de lutitas negras generadas por decantación desde plumas suspensivas en ambiente subácueo de muy baja energía, en el sector de costa afuera ('offshore') de un cuerpo lacustre hidrológicamente cerrado.

- El análisis del contenido de materia orgánica dispersa (palinofacies) realizado en las pelitas bituminosas de la Formación Mollar refleja que se corresponden con típicos depósitos lacustres con alto contenido de materia orgánica amorfa $(>90 \%)$ de origen algal y de restos de plantas terrestres altamente degradadas (Tipo I/II, tabla 2) (Conford, 1984). La importante preservación de los restos orgánicos y la presencia de sulfuros de hierro autígenos confirman la lenta tasa de acumulación sedimentaria combinada con una elevada productividad orgánica en un ambiente con muy limitada disponibilidad de oxígeno (fondo anóxico), producto de la estratificación de las aguas y una muy escasa remoción por corrientes de fondo.

- Las intercalaciones de areniscas finas que se registran en este intervalo estratigráfico se interpretan como la esporádica incursión de corrientes de turbidez de baja densidad, en tanto que los niveles de carbonatos estromatolíticos sugieren períodos de somerización y mayor oxigenación del sustrato.

- La presencia de ciclos granocrecientes de pequeña escala (PACs), con pasaje desde lutitas negras a intervalos heterolíticos y finalmente areniscas con óndulas orbitales y capas planas revelan procesos de progresiva somerización. El tope de los ciclos muestra un brusco pasaje a lutitas negras muy ricas en materia orgánica que sugieren un proceso de condensación sedimentaria que se atribuye a un marcado ascenso en el nivel de las aguas lacustres. Estas secuencias de alta frecuencia se interpretan como el resultado de episodios de expansión-retracción lacustre controlados por cambios climáticos.
- La sección superior de la Formación Mollar se caracteriza por sucesiones de pelitas de tonalidades más claras y profusa bioturbación, lo que refleja un mayor grado de oxigenación del sustrato. Se atribuyen al ambiente de costa afuera de un sistema lacustre holomíctico hidrológicamente abierto. Por su parte, los depósitos de areniscas que se asocian a estas facies finas se atribuyen a la acción de flujos friccionales hiperpicnales.

- En este intervalo estratigráfico, y con mayor frecuencia hacia los términos más altos de la Formación Mollar, aparecen asociaciones lacustres marginales representadas por sucesiones heterolíticas, típicas de la transición 'nearshore'- 'offshore', y areniscas con trazas fósiles indicadoras de condiciones de alta energía. Las estructuras primarias y los diseños de superposición de los cuerpos de areniscas sugieren diversos procesos de acumulación, tanto por flujos orbitales y combinados inducidos por olas normales y de tormenta, como por flujos unidireccionales.

- Además de los ciclos de alta frecuencia, en la Formación Mollar se definen tres ciclos sedimentarios de mayor escala, limitados por superficies transgresivas. Estos ciclos reflejan episodios mayores de expansión-contracción lacustres que se interpretan como el resultado de la interacción entre factores climáticos y tectónicos, éstos últimos relacionados con cambios en la tasa de subsidencia.

- El diseño de superposición general de la Formación Mollar es típicamente negativo o granocreciente y culmina con los depósitos netamente fluviales asignados estratigráficamente a la Formación Montaña. Esta megasecuencia refleja una constante reducción del espacio de acomodación sedimentaria en el depocentro de Santa Clara a medida que se produjo la acumulación de los depósitos de la Formación Mollar.

\section{Agradecimientos}

Los autores agradecen al CONICET (Consejo Nacional de Investigaciones Científicas y Técnicas, Argentina) por la financiación del Proyecto PIP\#5430/05 en el marco del cual se realizaron los trabajos de campo y de laboratorio. Expresan su reconocimiento al Dr. E. Morel y al Lic. D. Ganuza por su colaboración durante las tareas en el terreno, y a la Lic. N. Mego por su participación en la recolección de las muestras, así como en el procesamiento de las mismas en el laboratorio palinológico, trabajo realizado en conjunto con A. Moschetti en el IANIGLA, CCT-CONICET-Mendoza. A los Dres. V. Ramos, W. Volkheimer y A. Encinas por las valiosas sugerencias recibidas como revisores del manuscrito. 


\section{Referencias}

Artabe, A.E.; Spalletti, L.A.; Bodnar, J.; Morel, E.M. En prensa. Estudio paleoxilológico y sedimentológico de la Formación Montaña (Triásico), provincia de Mendoza, Argentina. Ameghiniana 46.

Barredo, S.P.; Ramos, V.A. 1997. Los depósitos de Rincón Blanco (Precordillera de San Juan); un rift triásico. In Jornadas sobre Geología de Precordillera, No. 2, Actas 1: 130-135. San Juan.

Batten, D.J. 1973. Use of palynologic assemblage-types in Wealden correlation. Palaeontology 16: 1-40.

Batten, D.J. 1979. Miospores and other acid-resistant microfossils from the Aptian/Albian of holes 400A and 402A, DSDP-IPOD leg 48, Bay of Biscay. In Initial reports of the Deep Sea Drilling Project 48 (Montadert, L.; Roberts, D.G.; editors): 579-587.

Batten, D.J. 1982. Palynofacies, palaeoenvironments, and petroleum. Journal of Micropalaeontology 1: 107-114.

Batten, D.J. 1996. Palynofacies and palaeoenvironmental interpretation. In Palynology: Principles and Applications (Jansonius, J.; Mcgregor, D.C.; editors). American Association of Stratigraphic Palynologists Foundation 26A: 1011-1064.

Batten, D.J. 1999. Palynofacies analysis. In Fossil Plants and Spores: Modern Techniques (Jones, T.P.; Rowe, N.P.; editors). Geological Society of London 12: 194-198.

Batten, D.J.; Morrison, L. 1983. Methods of palynological preparation for palaeoenvironmental, source potential and organic maturation studies. Norwegian Petroleum Directorate. Bulletin 2: 35-53.

Bellosi, E.S.; Jalfin, G.A.; Bossi, G.E.; Boggetti, D.; Chebli, P.; Muruga, C. 2001. Facies y Sedimentación. In El Sistema Triásico en la Argentina (Artabe, A.; Morel, E.; Zamuner, A.; editores). Fundación Museo de La Plata 'Francisco P. Moreno': 103-129.

Bohacs, K.M. 1998. Contrasting expressions of depositional sequences in mudrocks from marine and non-marine environments. In Shales and Mudstones 1 (Schieber, J.; Zimmerle, W.; Sethi, P.; editors). Stuttgart, Schweizerbartsche Verlagbuchhandlung: 33-78.

Bordas, A.F. 1944. Peces triásicos de la quebrada Santa Clara, provincias de San Juan y Mendoza. Physis 19: 453-460.

Boulter, M.C.; Riddick, A. 1986. Classification and analysis of palynodebris from the Palaeocene sediments of the Forties Field. Sedimentology 33: 871-876.

Breglia, S. 2000. Peces actinopterigios de la Quebrada de Santa Clara, norte de Mendoza. Aspectos taxonómicos y relaciones evolutivas. Tesis de Licenciatura/Master (Inédito), Universidad de Buenos Aires: 106 p.

Carroll,A.R.; Bohacs, K.M. 1999. Stratigraphic classification of ancient lakes: balancing tectonic and climatic controls. Geology 27: 99-102.

Carroll, A.R.; Bohacs, K.M. 2001. Lake-type controls on petroleum source rock potential in nonmarine basins. American Association of Petroleum Geologists, Bulletin 85: 1033-1053.

Casshyap, S.M.; Aslam, M. 1992. Deltaic and shoreline sedimentation in Saurashtra Basin, western India: an example of infilling in an Early Cretaceous failed rift. Journal of Sedimentary Petrology 62: 972-991.

Chan, M.; Dott, (Jr.) R. 1986. Depositional facies and progradational sequences in Eocene wave-dominated deltaic complexes, southwestern Oregon. American Association of Petroleum Geologists, Bulletin 70: 415-429.

Charrier, R. 1979. El Triásico en Chile y regiones adyacentes de Argentina: una reconstrucción paleogeográfica y paleoclimática. Comunicaciones 26: 1-37.

Coleman, J.; Wright, L. 1975. Modern river deltas: variability of processes and sand bodies. In Deltas, Models for Exploration (Broussard, M.; editor). Geological Society of Houston: 99-149.

Collinson, J.D.; Thompson, B.D. 1989. Sedimentary Structures, $2^{\text {nd }}$ Edition. Unwin Hyman Ltd.: 207 p.

Cornford, C. 1984. Source rocks and hydrocarbons of the North Sea. In Introduction to the Petroleum Geology of the North Sea (Glennie, K.W.; editor). Blackwell Scientific: 171-204.

Cortés, J.M.; González Bonorino, G.; Koukharsky, M.L.; Brodkorb, A.; Pereyra, F. 1999. Hoja Geológica 3369-03 Yalguaraz, Mendoza. Carta Geológica de la República Argentina, escala 1:100.000. Servicio Geológico Minero Argentino, Boletín 280: 176 p. Buenos Aires.

Cucchi, R.J. 1972. Geología y estructura de la Sierra de Cortaderas, San Juan-Mendoza, Argentina. Revista de la Asociación Geológica Argentina 27: 229-248.

Dam, G.; Surlyk, F. 1993. Cyclic sedimentation in a large wave and storm-dominated anoxic lake; Kap Stewart Formation (Rhaetian-Sinemurian), Jameson Land, East Greenland. In Sequence Stratigraphy and Facies Associations (Posamentier, H.W.; Summerhayes, C.P.; Haq, B.U.; Allen, G.P.; editors). International Association of Sedimentologists, Special Publication 18: 419-448.

Dam, G.; Surlyk, F.; Mathiesen, A.; Christiansen, F.G. 1995. Exploration significance of lacustrine forced regressions of the Rhaetian-Sinemurian Kap Stewart Formation, Jameson Land, East Greenland. Norwegian Petroleum Society, Special Publications 5: 511-527.

Dean, W.E.; Fouch, T.D. 1983. Lacustrine environment. In Carbonate Depositional Environments (Scholle, P.A.; Bebout, D.G.; Moore, C.H.; editors). American Association of Petroleum Geologists, Memoir 33: 97-130. Tulsa.

Elliot, T. 1986. Deltas. In Sedimentary Environments and Facies 2nd edition (Reading, H.G.; editor): 113-154. Blackwell, Oxford.

Eugster, H.P.; Kelts, K. 1983. Lacustrine chemical sediments. In Chemical Sediments and Geomorphology: Precipitates and Residua in the Near-Surface Envi- 
ronment (Goudie, A.S.; Pye, K.; editors). Academic Press: 321-368. New York.

Eyles, N.; Clark, B.M. 1986. Significance of hummocky and swaley cross-stratification in late Pleistocene lacustrine sediments of the Ontario basin, Canada. Geology 14: 679-682.

Fisher, M.J. 1980. Kerogen distribution and depositional environments in the Middle Jurassic of Yorkshire U.K. In Proceedings of the $4^{\text {th }}$ International Palynological Conference (Lucknow) 2: 574-580.

Furque, G.; Cuerda, A. 1979. Precordillera de La Rioja, San Juan y Mendoza. In Geología Regional Argentina (Turner, J.C.M.; editor). Academia Nacional de Ciencias 1: 455-522. Córdoba.

Ghibaudo, G. 1992. Subaqueous sediment gravity flow deposits: practical criteria for their field description and classification. Sedimentology 39: 423-454.

Goodwin, P.W.; Anderson, E.J. 1985. Punctuated aggradational cycles: a general hypothesis of episodic stratigraphic accumulation. Journal of Geology 93: 515-533.

Goodwin, P.W.; Anderson, E.J.; Goodman, W.M.; Saraka, L.J. 1986. Punctuated aggradational cycles: implications for stratigraphic analysis. Paleoceanography 1 : 417-429.

Harrington, H. 1971. Descripción geológica de la Hoja 22c, Ramblón, Provincias de Mendoza y San Juan. Dirección Nacional de Geología y Minería, Boletín 114: 1-81. Buenos Aires.

Harrington, H.J.; de Benedetti, J.F. 1941. Investigación geológica en las sierras de Villavicencio y Mal País (Mendoza). Dirección Nacional de Geología y Minería, Boletín 49: 1-56.

Hart, G.F. 1986. Origin and classification of organic matter in clastic systems. Palynology 10: 1-23.

Horton, B.K.; Schmitt, J.G. 1996. Sedimentology of a lacustrine fan-delta system. Miocene Horse Camp Formation, Nevada, U.S.A. Sedimentology 43: 133-155.

Hutchinson, P. 1973. Pseudobeaconia, A perleidiform fish from the Triassic Santa Clara Formation, Argentina. Breviora 398: 1-24.

Johnson, C.L.; Graham, S.A. 2004. Cycles in perilacustrine facies of Late Mesozoic rift basins, southeastern Mongolia. Journal of Sedimentary Research 74: 786-804.

Katz, B.J. 1995. Factors controlling the development of lacustrine petroleum source rocks-an update. In $\mathrm{Pa}$ leogeography, Paleoclimate, and Source Rocks (Huc, A.Y.; editor). American Association of Petroleum Geologists. Studies in Geology 40: 61-79.

Kokogián, D.; Boggetti, D.; Rebay, G. 1988. Cuenca Cuyana. El análisis estratigráfico secuencial en la identificación de entrampamientos sutiles. In Congreso Nacional Exploración de Hidrocarburos, No. 1, Actas 2: 649674. Buenos Aires.

Kokogián, D.; Fernández Seveso, F.; Mosquera, A. 1993. Las secuencias sedimentarias triásicas. In Congreso Geológico Argentino, No. 12 y Congreso de Explo- ración de Hidrocarburos, No. 2. Relatorio Geología y Recursos Naturales de Mendoza 1 (7): 65-78. Buenos Aires.

Kokogián, D.; Spalletti, L.; Morel, E.; Artabe, A.; Martínez, R.; Alcober, O.; Milana, J.; Zavattieri, A.; Papú, O. 1999. Los depósitos continentales triásicos. In Geología Argentina (Caminos, R.; editor). Secretaría de Minería, Servicio Geológico Argentino, Instituto de Geología y Recursos Minerales. Anales 29: 377-398.

Kokogián, D.; Spalletti, L.; Morel, E.; Artabe, A.; Martínez, R.; Alcober, O.; Milana, J.; Zavattieri, A.; Papú, O. 2001. Estratigrafía del Triásico Argentino. In El Sistema Triásico en la Argentina (Artabe, A.; Morel, E.; Zamuner, A.; editores). Fundación Museo de La Plata 'Francisco P. Moreno': 23-54.

Legarreta, L.; Gulisano, C.; Legarreta, L.; Gulisano, C. 1989. Análisis estratigráfico secuencial de la Cuenca Neuquina (Triásico superior-Terciario inferior). In Cuencas Sedimentarias Argentinas (Chebli, G.; Spalletti, L.; editores). Serie Correlación Geológica 6: 221-243.

López Arbarello, A.; Zavattieri, A.M. 2008. Systematic revision of Pseudobeaconia Bordas, 1944, and Mendocinichthys Whitley, 1953 (Actinopterygii: 'Perleidiformes') from the Triassic of Argentina. Palaeontology 51 (5): 1025-1052.

López Gamundí, O.R. 1994. Facies distribution in an asymmetric halfgraben: the northern Cuyo Basin(Triassic), western Argentina. In International Sedimentological Congress, No. 14. Abstracts S1: 6-7. Recife.

López Gamundí, O.R.; Astini, R.A. 1994. Alluvial fanlacustrine association in the fault tip end of a half -graben, northern Triassic Cuyo basin, western Argentina. Journal of South American Earth Sciences 17: 235-265.

Lowe, D.R. 1982. Sediment gravity flows: II. Depositional models with special reference to the deposits of highdensity turbidity currents. Journal of Sedimentary Petrology 52: 279-297.

Mack,G.H.; Stout, D.M. 2005. Unconventional distribution of facies in a continental rift basin: the Pliocene-Pleistocene Mangas Basin, south-western New Mexico, U.S.A. Sedimentology 52: 1187-1205.

Marshall, J.D. 2000. Sedimentology of a Devonian faultbounded braidplain and lacustrine fill in the lower part of the Skrinkle Sandstones, Dyfed, Wales. Sedimentology 47: 325-342.

Martel,A.T.; Gibling, M.R. 1991. Wave-dominated lacustrine facies and tectonically controlled cyclicity in the Lower Carboniferous Horton Bluff Formation, Nova Scotia, Canada. In Lacustrine Facies Analysis (Anadón, P.; Cabrera, L.; Kelts, K.; editors). International Association of Sedimentologists, Special Publication 13: 223-243.

Martinek, K.; Blecha, M.; Danek, V.; Francu, J.; Hladikova, J.; Johnova, R.; Ulicny, D. 2006. Record of palaeoen- 
vironmental changes in a Lower Permian organic-rich lacustrine succession: integrated sedimentological and geochemichal study of the Rudnik member, Krkonose Piedmont Basin, Czech Republic. Palaeogeography, Palaeoclimatology, Palaeoecology 230: 85-128.

Melchor, R.N. 2007. Changing lake dynamics and sequence stratigraphy of synrift lacustrine strata in a half-graben: and example from the Triassic Ischigualasto-Villa Unión Basin, Argentina. Sedimentology 54: 1417-1446.

Morel, E.M. 1994. El Triásico del Cerro Cacheuta, Mendoza (Argentina). Parte I: Geología, contenido paleoflorístico y cronoestratigráfico. Ameghiniana 31: 161-176.

Mpodozis, C.; Kay, S. 1990. Provincias magmáticas ácidas y evolución tectónica de Gondwana: Andes chilenos $\left(28^{\circ}-31^{\circ} \mathrm{S}\right)$. Revista Geológica de Chile 17 (2): 153-180.

Nesossi, D.A. 1945. Contribución al conocimiento geológico de 'Santa Clara', Provincias de Mendoza y San Juan. Tesis Doctoral (Inédito), Universidad Nacional de La Plata, Facultad de Ciencias Naturales y Museo: 70 p.

Oboh-Ikuenobe, F.E.; Yepes, O. 1997. Palynofacies analysis of sediments from the Côte d'Ivoire-Ghana transform margin: preliminary correlation with some regional events in the eastern Equatorial Atlantic. Palaeogeography, Palaeoclimatology, Palaeoecology 129: 291-314. doi:10.1016/S0031-0182(96)00125-3

Oboh-Ikuenobe, F.E.; Obi, C.G.; Jaramillo, C.A. 2005. Lithofacies, palynofacies, and sequence stratigraphy of Palaeogene strata in Southeastern Nigeria. Journal of African Sciences 41: 79-102.

Olsen, P.E. 1990. Tectonic, climatic and biotic modulation of lacustrine ecosystems-examples from Newark Supergroup of eastern North America. In Lacustrine Basin Exploration: Case Studies and Modern Analogs (Kats, B.J.; editor). American Association of Petroleum Geologists, Memoir 50: 209-224.

Orton, G.J.; Reading, H.G. 1993. Variability of deltaic processes in terms of sediment supply, with particular emphasis on grain size. Sedimentology 40: 475-512.

Pietras, J.T.; Carroll,A.R. 2006. High-resolution stratigraphy of an underfilled lake basin: Wilkins Peak Member, Eocene Green River Formation, Wyoming, U.S.A. Journal of Sedimentary Research 76: 1197-1214.

Platt, N.H.; Wright, V.P. 1991. Lacustrine carbonates: facies models, facies distributions and hydrocarbon aspects. In Lacustrine Facies Analysis (Anadón, P.; Cabrera, L; Kelts, K.; editors). International Association of Sedimentologists, Special Publication 13: 57-74.

Potter, P.E.; Maynard, J.B.; Pryor, W.A. 1980. Sedimentology of Shale. Springer-Verlag: 306 p.

Rajchl, M.; Ulicny, D.; Mach, K. 2008. Interplay between tectonics and compaction in a rift-margin, lacustrine delta system: Miocene of the Eger Graben, Czech Republic. Sedimentology 55: 1419-1447.
Ramos, V.A.; Kay, S.M. 1991. Triassic rifting and associated basalts in the Cuyo Basin, central Argentina. In Andean Magmatism and its Tectonic Setting (Harmon, R.S.; Rapela, C.W; editors). Geological Society of America, Special Publication 265: 79-91.

Reading, H.; Collinson, J. 1996. Clastic Coasts. In Sedimentary Environments: Processes, Facies, and Stratigraphy (3rd. Edition) (Reading, H.; editor). Blackwell Science: 154-231.

Reineck, H.E.; Singh, I.B. 1980. Depositional Sedimentary Environments. Springer-Verlag: 439 p.

Smith, G.A. 1986. Coarse-grained nonmarine volcaniclastic sediment: terminology and depositional process. Geological Society of America Bulletin 97: 1-10.

Spalletti, L.A. 1997. Sistemas deposicionales fluvio-lacustres en el rift triásico de Malargüe (sur de Mendoza, República Argentina). Anales de la Academia $\mathrm{Na}-$ cional de Ciencias Exactas, Físicas y Naturales 49: 109-124. Buenos Aires.

Spalletti, L.A. 1999. Cuencas triásicas del oeste argentino: origen y evolución. Acta Geológica Hispánica 32 (1-2): 29-50.

Spalletti, L. 2001a. Evolución de las cuencas sedimentarias. In El Sistema Triásico en la Argentina (Artabe, A.; Morel, E.; Zamuner, A.; editores). Fundación Museo de La Plata 'Francisco P. Moreno': 81-101.

Spalletti, L. 2001b. Modelo de sedimentación fluvial y lacustre en la rampa de un hemigraben: el Triásico de la Precordillera Occidental de San Juan, República Argentina. Revista de la Asociación Geológica Argentina 56: 189-210.

Stipanicic, P.N. 1969. Las sucesiones triásicas argentinas. Primer Coloquio de la UICG: La Estratigrafía del Gondwana. UNESCO, Ciencias de La Tierra 2:11211149. Buenos Aires.

Stipanicic, P.N. 1979. El Triásico del valle del Río de Los Patos (provincia de San Juan). In Geología Regional Argentina (Turner, J.C.M.; editor). Academia Nacional de Ciencias de Córdoba 1: 695-744.

Stipanicic, P.N. 1983. The Triassic of Argentina and Chile. In The Phanerozoic Geology of the World. The Mesozoic (Moullade, M.; Nairn, A.E.M.; editors). Elsevier: 181-199.

Stipanicic, P.N.; Marsicano, C.A. 2002. Triásico. Léxico Estratigráfico de la Argentina, No. 8. Asociación Geológica Argentina, Serie 'B' (Didáctica y Complementaria) 26:370 p.

Stipanicic, P.N.;Zavattieri, A.M.; Marsicano, C. 2002. Grupo Peñasco. In Triásico (Stipanicic, P.N.; Marsicano, C.A.; editores). Léxico Estratigráfico de la Argentina, No. 8. Asociación Geológica Argentina, Serie 'B' (Didáctica y Complementaria) 26: 210-212.

Suárez, M.; Bell, M. 1992. Triassic rift-related sedimentary basins in northern Chile $\left(22^{\circ}-30^{\circ} \mathrm{S}\right)$. Journal of South American Earth Sciences 6: 109-121.

Talbot, M.R.; Allen, P.A. 1996. Lakes. In Sedimentary Environments: Processes, Facies and Stratigraphy (Reading, H.G.; editor). Blackwell Science: 83-124. 
Tankard, A.J.; Uliana, M.A.; Welsink, H.J.; Ramos, V.A.; Turic, M.; Franca, A.B.; Milani, E.J.; Brito Neves, B.B.; de Eyles, N.; Skarmeta, J.; Santa Ana, H.; Wiens, F.; Cirbián, M.; López Paulsen, O.; Germs, G.J.B.; De Witt, M.J.; Machacha, T.; Miller, R.McG. 1995. Tectonic controls of basin evolution in Southwestern Gondwana during the Phanerozoic. In Petroleum Basins of South America (Tankard, A.J.; Suárez Soruco, R.; Welsink, H.J.; editors). American Association of Petroleum Geologists, Memoir 62: 5-52.

Tribovillard, N.P.; Gorin, G.E. 1991. Organic facies of the Early Albian Niveau Paquier, a key black shale horizon of the Marnes Bleues Formation in the Vocontian Trough (Subalpine Ranges, SE France). Palaeogeography, Palaeoclimatology, Palaeoecology 85: 227-237.

Tyson, R.V. 1987. The genesis and palynofacies characteristics of marine petroleum source rocks. In Marine Petroleum Source Rocks (Brooks, J.; Fleet, A.J.; editors). Geological Society Special Publication 26: 47-67.

Tyson, R. 1995. Sedimentary organic matter. Organic facies and palynofacies. Chapman and Hall: $621 \mathrm{p}$.

Uliana, M.A.; Biddle, K.T. 1988. Mesozoic-Cenozoic paleogeographic and geodynamic evolution of southern South America. Revista Brasileira de Geociencias 18: 172-190.

Uliana, M.A.; Biddle, K.T.; Cerdan, J. 1989. Mesozoic extension and the formation of Argentine sedimentary basins. In Extensional Tectonics and Stratigraphy of North Atlantic Margins (Tankard, A.J.; Balkwill,
H.R.; editors). American Association of Petroleum Geologists, Memoir 46: 599-614.

Van Bergen, P.F.; Janssen, N.M.M.; Alferink, M.; Kerp, J.H.F. 1990. Recognition of organic matter types in standard palynological slides. In Proceedings of the International Symposium on Organic Petrology, Zeist January 1990 (Fermont, W.J.J.; Weegink, J.W.; editors). Mededelingen Rijks Geologische Dienst, 45: 23-37.

Van der Zwan, C.J. 1990. Palynostratigraphy and palynofacies reconstruction of the Upper Jurassic to lowermost Cretaceous of the Draguen Field, offshore Mid Norway. Palaeobotany and Palynology 62: 157-186.

Villar, H.J.; Puttmann, W.; López Gamundí, O.R. 1991. Characterization of kerogen from Triassic oil shales of the Calingasta Valley, Cuyo Basin, Argentina. In International Meeting on Organic Geochemistry, No. 15. European Association of Organic Geochemics: 171-172.

Whitaker, M.F. 1984. The usage of palynology in definition of Troll Field geology. In Reduction of uncertainties in innovative reservoir geomodelling. 'Offshore' Northern Seas Conference, No. 6, and Exhibition, Stavanger. Norsk Petroleums-forening, Paper G6: 44 p.

Yrigoyen, M.R.; Stover, L.W. 1969. La palinología como elemento de correlación del Triásico en la Cuenca Cuyana. In Jornadas Geológicas Argentinas, No. 4, Actas 2: 427-447. Buenos Aires. 
LÁMINAS 1-3 


\section{LAMINA 1}

Fotografías de las palinofacies lacustres representativas de la Formación Mollar.

\section{Figuras}

A-B Palinofacies (MPLP 8779). A. Materia orgánica sedimentaria original ( $1^{\circ}$ preparado) dominada por material amorfo finamente dividido (partículas $<5 \mu \mathrm{m}$ de diámetro), posee color marrón-negro a marrón-gris, de aspecto coloidal a subcoloidal (detritos inorgánicos asociados), masas pequeñas o grumos de MOA y en menor proporción partículas negras opacas (x20) de origen algal; B. $\left(2^{\circ}\right.$ preparado, luego de tratamientos OUF) se eliminó gran parte del material amorfo finamente dividido quedando masas de materia orgánica amorfa que tiene color marrón-negro y escasos fitoclastos estructurados (FCE) con forma de tablillas y partículas negras opacas (x20).

C-D Palinofacies (MPLP 8780). C. Materia orgánica sedimentaria original ( $1^{\circ}$ preparado) dominada por material amorfo finamente dividido (partículas $<5 \mu \mathrm{m}$ de diámetro), que posee color marrón-negro a marrón-gris, de aspecto subcoloidal (detritos inorgánicos asociados), algunos fragmentos bioestructurados negros opacos (FCE) (x40); D. ( $2^{\circ}$ preparado, luego de tratamientos OUF) muestra una mayor diversidad de componentes orgánicos (mayormente de origen terrestre) al haber eliminado el material amorfo finamente dividido, indica origen mayormente terrestre: palinomorfos (PAL); fitoclastos no estructurados (FCNE), partículas negras opacas (PNO) $\mathrm{y}$ fragmentos de MOA que tienen color pardo y aspecto granular (x20).

E-F Palinofacies (MPLP 8781-A). E. Materia orgánica sedimentaria original ( $1^{\circ}$ preparado) dominada por material amorfo en masas densas, agregadas, que son de color marrón-negro y material amorfo finamente dividido (partículas $<5 \mu \mathrm{m}$ de diámetro), son comunes las partículas negras opacas (x10); F. ( $2^{\circ}$ preparado, luego de tratamientos OUF) las masas de MOA han sido desagregadas, se observan fitoclastos parcialmente degradados en los que aparecen relictos de las fibras vegetales originales, indicando derivación de material vegetal terrestre (x20).

G-H Palinofacies (MPLP 8784). G. Materia orgánica sedimentaria original ( $1^{\circ}$ preparado) dominada por material amorfo, de aspecto granular, fibroso a esponjoso, agregado en masas cuyo color es marrón-negro, con fitoclastos no estructurados incluidos o adheridos y partículas negras opacas (x10); H. $\left(2^{\circ}\right.$ preparado, luego de tratamientos OUF) prácticamente se mantiene la misma composición de los componentes orgánicos originales, pero con menor proporción de MOA finamente dividida (x10); indica material de procedencia mayormente algal. 

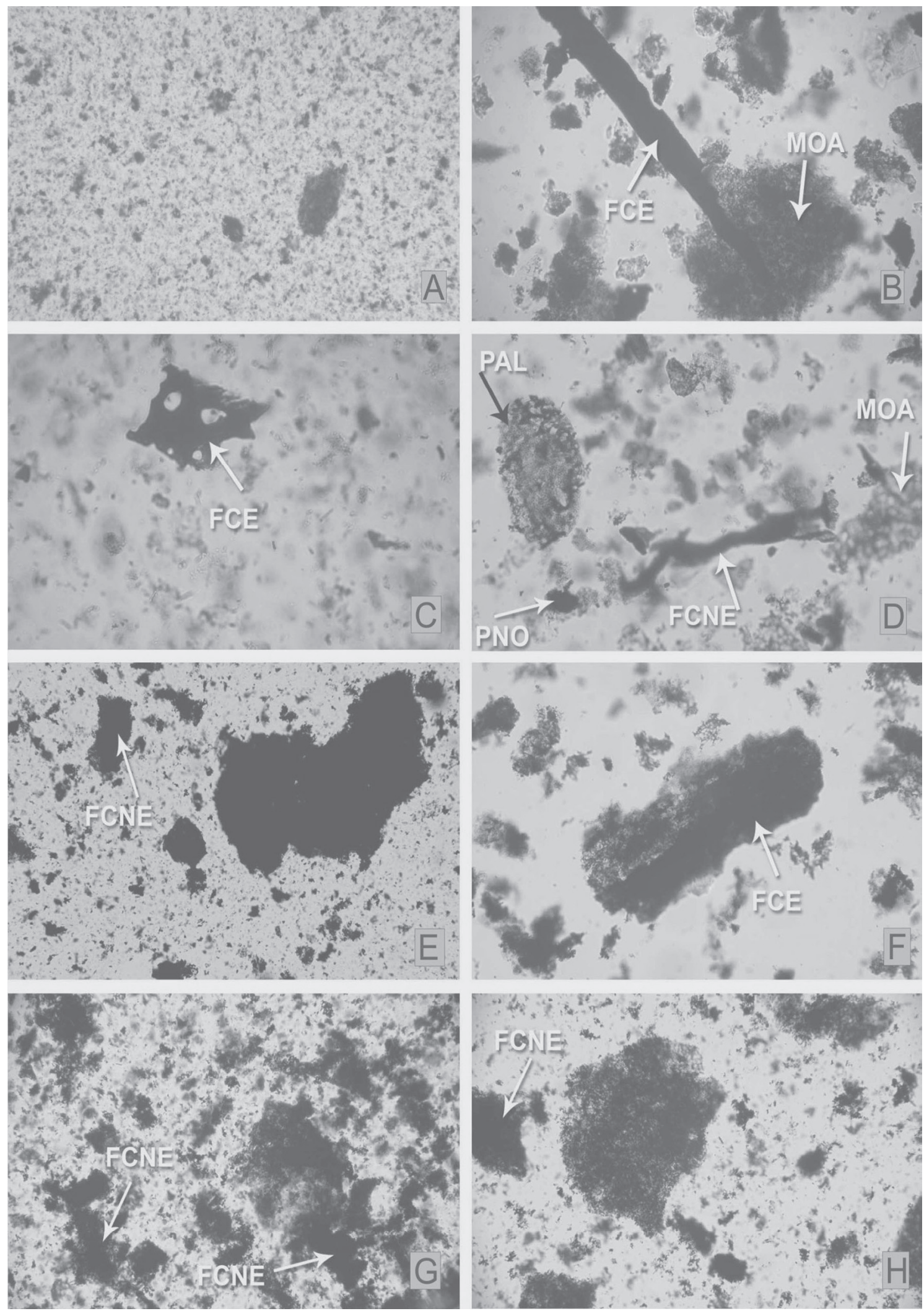


\section{LÁMINA 2}

Tipos principales de materia orgánica amorfa (MOA) que dominan en las palinofacies lacustres de la Formación Mollar

\section{Figuras}

A Masas o grumos de MOA de color marrón. La flecha señala una partícula de MOA de forma oval que podría ser derivada de un zooclasto (faecal pellets). MPLP 8774 A (x40).

B Agregados orgánicos amorfos (MOA), de aspecto mayormente granular a esponjoso, que posee color marrón-negro sin evidencia de estructura del material orgánico de origen. Tipo de MOA muy abundante en estas palinofacies (MPLP 8782B, x20).

C Partícula de MOA con una forma bien definida aunque sin relictos de estructuras biológicas originales; sin embargo la forma cuadrangular del clasto puede indicar un origen vegetal (MPLP 8774B, x100).

D Materia orgánica amorfa, de aspecto granular-pelicular, cuyo color es pardo claro; la falta de una forma definida de esta partícula y la presencia de inclusiones, indican posible origen algal altamente degradado (MPLP 8782B, $\mathrm{x} 40$ ).

E La flecha negra señala una partícula de MOA de aspecto granular a esponjoso, que tiene color marrón-claro producto de la alta degradación (bacteriana) de un fragmento de fitoclasto en el que todavía se alcanzan a observar algunos restos de tejidos fibrosos originales. La flecha blanca señala un fitoclasto opaco (FCNE), angular, altamente corroído; los orificios pueden deberse a estructuras biológicas originales y/o a corrosión pirítica y/o fúngica (MPLP 8787A, x40).

F Masa de materia orgánica granular de color marrón con inclusiones de partículas orgánicas pequeñas; presenta orificios de corrosión pirítica secundaria (flecha blanca); la falta de estructura visible y la masa informe agregada, bordes irregulares, señala posible origen algal (MPLP 8786A, x20).

G Partícula de MOA de color pardo-claro, de aspecto granular-esponjoso, con inclusiones de pequeñas partículas marrones y palinomorfo (PAL); su forma indefinida y los bordes irregulares, además de las inclusiones de material terrígeno indican que podría tratarse de material de origen algal, altamente degradado (MPLP 8787C, x20).

H Masas de MOA cuyo color es marrón, marrón-amarillo a marrón-anaranjado, de aspecto esponjoso a granular; la forma de los bordes relativamente definidos y relictos de estructuras fibrosas originales, indican material amorfo derivado de material vegetal (MPLP 8792B, x20).

I Masas de materia orgánica amorfa granular, de aspecto coloidal y/o formando grumos, que posee color marrónnegro de probable origen algal altamente degradado (MPLP 8794B, x20).

J Masas de MOA de aspecto granular, que presentan color marrón negro; fitoclastos pequeños y/o palinomorfos (PAL) incluidos y/o adheridos; algunas presentan relictos de material fibroso (FCNE) que indica degradación de restos vegetales terrestres (MPLP 8794B, x40).

K Fragmentos de MOA de aspecto granular a esponjoso, son de color marrón oscuro con bordes amarillos-anaranjados, derivada de material vegetal altamente degradado; se observan aún relictos de las fibras originales de los fitoclastos que le dan origen (MPLP 8792B, x20).

L Fitoclasto estructurado fibroso con aspecto granular a esponjoso que da origen a MOA cuyo color es marrón a marrón pardo, en los que se observan las fibras originales del material vegetal de tipo leñoso (MPLP 8792A'. $\mathrm{x} 40)$. 


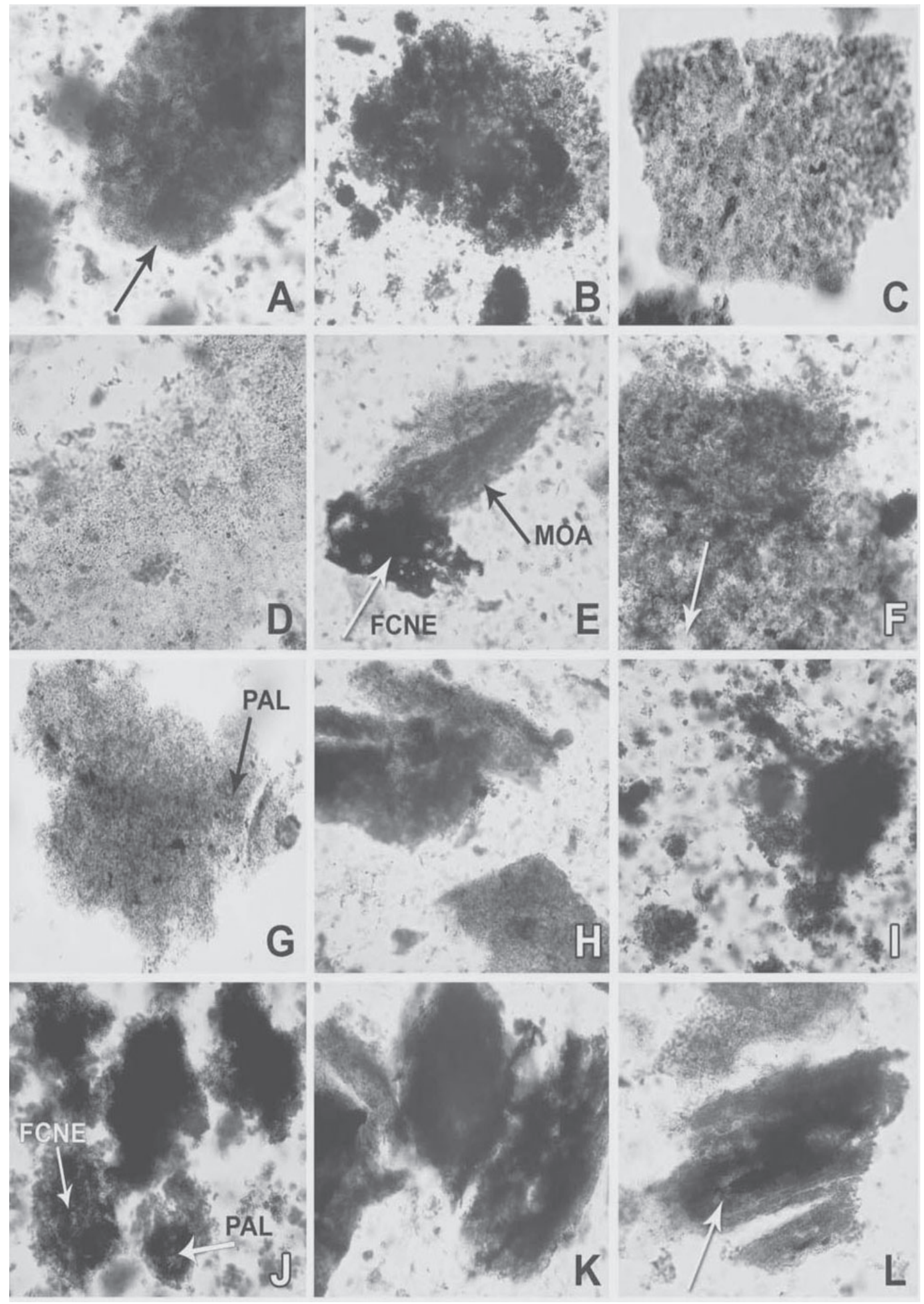




\section{LÁMINA 3}

Constituyentes principales de la materia orgánica sedimentaria halladas en la sucesión lacustre de la Formación Mollar

\section{Figuras}

A Palinomorfo (grano de polen de gimnosperma) (PAL), muy degradado por pirita; fitoclasto estructurado (FCE) negro (oxidado) con forma de astilla sin estructura interna visible; partículas negras opacas (PON), angulares (vitrinita). MPLP 8775C (x20).

B Fitoclasto bioestructurado (FCE), de color marrón, exhibe estructura fibrosa paralela (posible xilema secundario), con forma de tablilla; en los bordes se observa materia orgánica amorfa (MOA) que tiene color amarillo pálido, mostrando granulación producida por ataque bacterial. MPLP 8792D (x40).

C Tubo y/o filamento de color negro (materia orgánica estructurada) que puede ser derivado tanto de origen algal como de plantas vasculares; partículas negras opacas (PNO), angulosas (vitrinita) y el fondo está cubierto por material amorfo finamente dividido de color gris-negro. MPLP 8771B (x20).

D Tubo o filamento no ramificado (de posible origen algal) (fitoclasto estructurado); el fondo cubierto por materia orgánica amorfa finamente dividida de color gris y grumos de materia orgánica amorfa que posee color marrón. MPLP 8771B (x20).

E Posible zooclasto, parcialmente degradado por ataque bacterial, MPLP 8777C (x100).

F Palinomorfo: hongo multicelular ('cuerpo fructificante') de color marrón oscuro - melanización- (exposición a oxígeno atmosférico que indica un origen terrestre) y materia orgánica amorfa (MOA), de aspecto granular y que posee color amarillo claro que indica ataque bacteriano. MPLP $8792 \mathrm{C}$ (x100).

G Fitoclasto bioestructurado de color marrón oscuro, posiblemente derivado de tejidos cuticulares con preservación de las células y perforaciones producidas por corrosión pirítica y/o ataque de hongos. MPLP 8775C (x40).

H Masa de materia orgánica amorfa (MOA) que tiene color amarillo claro, de aspecto granular y palinomorfos adheridos o incluidos en ella (PAL). MPLP 8792E (x40).

I Fitoclasto estructurado, altamente degradado por ataque bacteriano dado el aspecto granular, exhibe aún relictos de estructura fibrosa paralela (detrito de plantas vasculares). MPLP-8782 B (x40).

J Grano de polen bisacado de gimnosperma, completamente degradado y corroído por pirita; no se observan los rasgos estructurales originales. MPLP 8775C (x40).

K Fitoclasto bioestructurado altamente degradado (FCE) que se presenta con color pardo claro, semitransparente, posiblemente resto de tejido cuticular (?epidermis foliar); grumos y masas de materia orgánica amorfa (MOA) de color marrón oscuro y también en finas partículas diseminadas. MPLP 8792A' (x40).

L Espora trilete (pteridófitas) totalmente carbonizada y completamente corroída por pirita; sólo se observa el contorno original de la espora. MPLP 8769B x100.

M Partícula de resina que tiene color anaranjado intenso, con vértices redondeados y superficie de apariencia lustrosa y vítrea. MPLP 8792C (x100).

N Fitoclasto bioestructurado cuyo color es pardo, altamente corroído por pirita y degradado por posible ataque de hongos y/o bacteriano, probable resto de tejido de plantas vasculares. MPLP 8787B (x40).

O Materia orgánica amorfa de aspecto granular, derivada de la intensa degradación de un fitoclasto (posiblemente xilema) originariamente bioestructurado; la flecha blanca señala las estructuras celulares relictuales, altamente desmembradas por la degradación bacteriana y/o fúngica. MPLP 8792D (x40). 

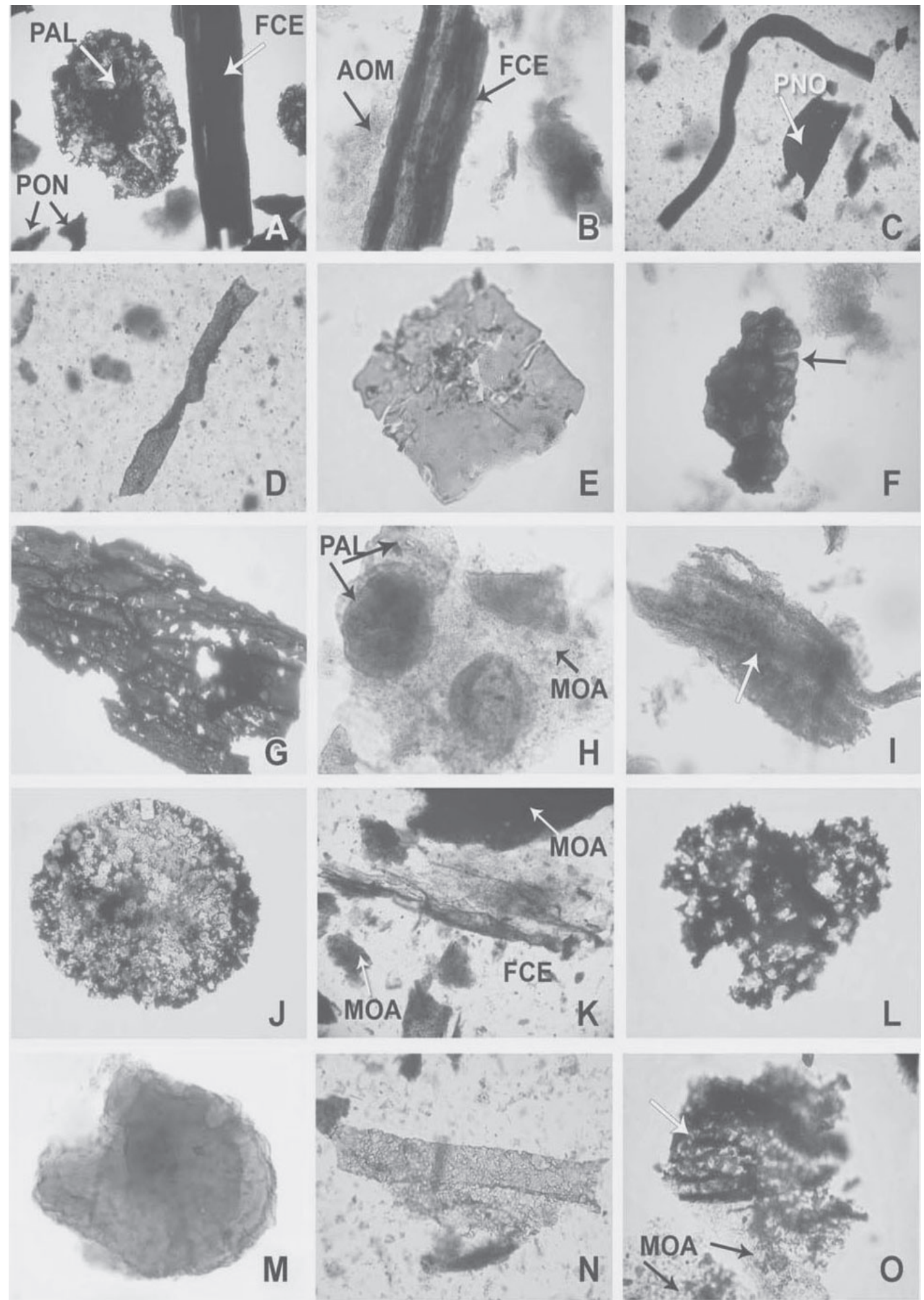